\title{
Ophthalmology
}

\section{The Ocular Surface Frailty Index as a predictor of ocular surface symptoms onset after cataract surgery \\ --Manuscript Draft--}

\begin{tabular}{|c|c|}
\hline Manuscript Number: & OPHTHA_2019_193R4 \\
\hline Article Type: & Manuscript \\
\hline Corresponding Author: & $\begin{array}{l}\text { Edoardo Villani } \\
\text { University of Milan } \\
\text { Milan, ITALY }\end{array}$ \\
\hline First Author: & Edoardo Villani \\
\hline \multirow[t]{8}{*}{ Order of Authors: } & Edoardo Villani \\
\hline & Luca Marelli \\
\hline & Francesco Bonsignore \\
\hline & Stefano Lucentini \\
\hline & Saverio Vincenzo Luccarelli \\
\hline & Matteo Sacchi \\
\hline & Massimiliano Serafino \\
\hline & Paolo Nucci \\
\hline Abstract: & 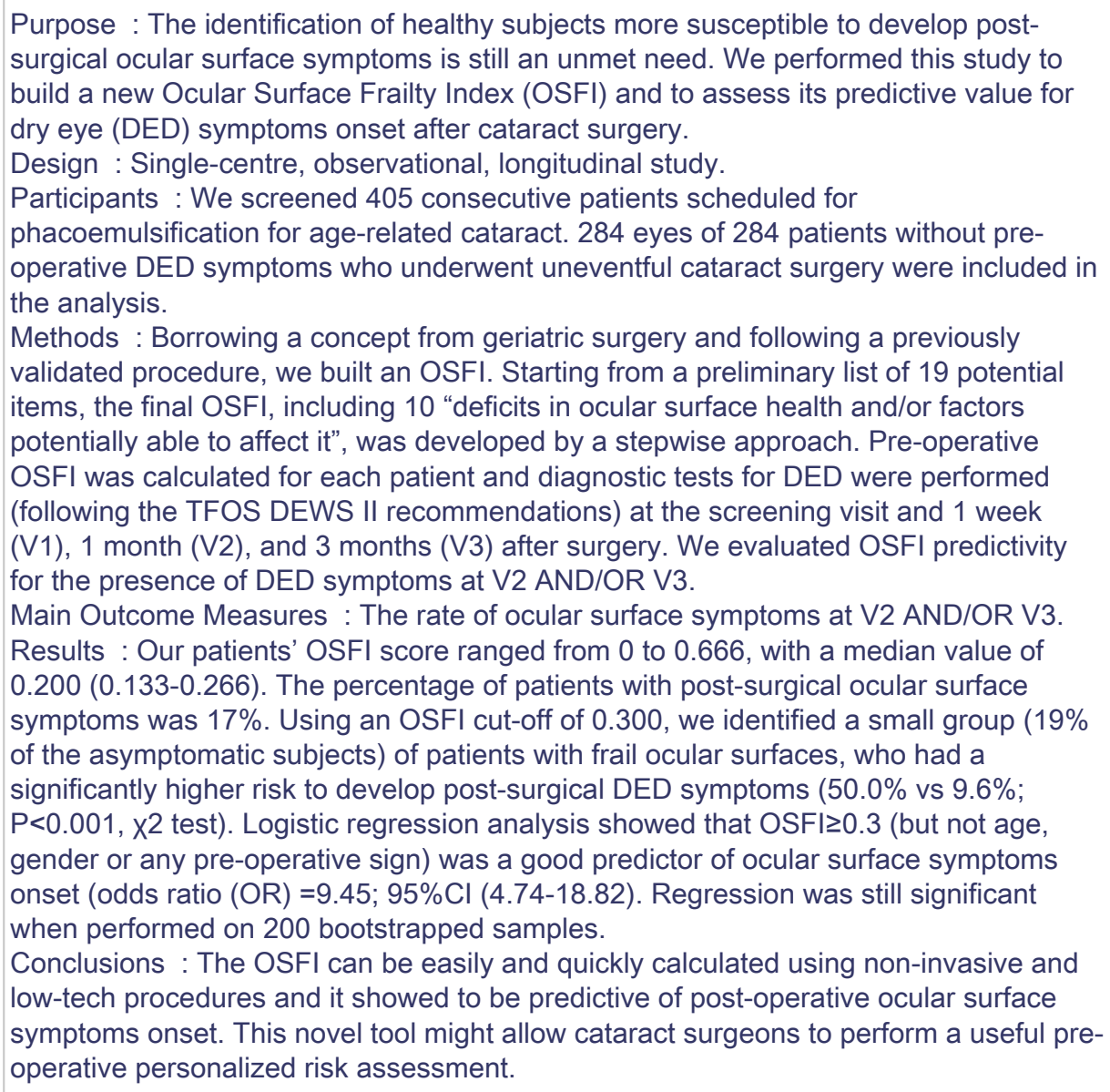 \\
\hline \multirow[t]{2}{*}{ Suggested Reviewers: } & $\begin{array}{l}\text { Jose Manuel Benitez-del-Castillo } \\
\text { benitezcastillo@gmail.com } \\
\text { Expert in dry eye and anterior segment surgery }\end{array}$ \\
\hline & Luca Agnifili \\
\hline
\end{tabular}


l.agnifili@unich.it

Expert in dry eye and anterior segment surgery

Pedram Hamrah

PHamrah@tuftsmedicalcenter.org

Expert in dry eye and anterior segment surgery

Christophe Baudouin

cbaudouin@15-20.fr

Expert in dry eye and anterior segment surgery

Murat Dogru

muratodooru2012@yahoo.com

Expert in dry eye and anterior segment surgery

Opposed Reviewers:

Response to Reviewers: 
Milan, December 11th 2019

To Prof. Stephen D. McLeod, Editor-in-Chief, Ophthalmology

\section{Dear Prof McLeod,}

Thank you for the opportunity to revise and improve our manuscript Ref: OPHTHA_2019_193R3, "The Ocular Surface Frailty Index as a predictor of ocular surface symptoms onset after cataract surgery".

We tried to address all the remaining concerns of the reviewer.

We hope that you will find our manuscript acceptable for publication in this revised form.

Kind regards

Sincerely,

Edoardo Villani 
Point by point response to editors and reviewers (R4).

Changes in the document are highlighted in the "track changes" version of the manuscript.

\begin{tabular}{|c|c|c|}
\hline $\begin{array}{l}\text { Suggestions, questions, or } \\
\text { comments from the } \\
\text { Reviewer \#2 }\end{array}$ & Author's Response & Change in the manuscript \\
\hline $\begin{array}{l}\text { Reviewer 2: The authors have } \\
\text { re-revised their manuscript } \\
\text { and made substantive } \\
\text { changes. There are some } \\
\text { minor concerns. My } \\
\text { comments refer to the } \\
\text { chronology of the marked up } \\
\text { revised copy: }\end{array}$ & & \\
\hline $\begin{array}{l}1 \text { - Lines } 129-130 \text { are written } \\
\text { as a double negative }\end{array}$ & Changed as suggested & $\begin{array}{l}\text { Patients with DED signs } \\
\text { without symptoms were } \\
\text { included. } 19\end{array}$ \\
\hline $\begin{array}{l}2 \text { - Line } 146 ; \text { the word "on" } \\
\text { should be changed to the } \\
\text { regarding }\end{array}$ & Changed as suggested & $\begin{array}{l}\text { Each patient completed a } \\
\text { questionnaire regarding } \\
\text { his/her medical history }\end{array}$ \\
\hline $\begin{array}{l}3 \text { - Lines } 185-186 \text {; please } \\
\text { explain the phrase "doesn't } \\
\text { saturate too early." }\end{array}$ & Explained as suggested & $\begin{array}{l}\text {... paying attention to } \\
\text { include variables which were } \\
\text { associated with ocular } \\
\text { surface health status, whose } \\
\text { prevalence generally increase } \\
\text { with age, and which } \\
\text { don't saturate too early (for } \\
\text { instance, presbyopia is nearly } \\
\text { universal by age } 55 \text {, } \\
\text { saturating too early to be } \\
\text { included in this type of frailty } \\
\text { index) }\end{array}$ \\
\hline $\begin{array}{l}4 \text { - Lines } 290-293 \text { are of } \\
\text { questionable value and } \\
\text { could/should be removed }\end{array}$ & $\begin{array}{l}\text { Thank you for your observation. } \\
\text { In order to address your concern } \\
\text { and, at the same time, to avoid to } \\
\text { skip an essential concept, we } \\
\text { rephrased this sentence. }\end{array}$ & $\begin{array}{l}\text { Even if the advanced age can } \\
\text { carry increased risk of post- } \\
\text { surgical adverse events, } \\
\text { the chronological age is not } \\
\text { suitable to be used as a tool } \\
\text { for pre-operative risk }\end{array}$ \\
\hline
\end{tabular}




\begin{tabular}{|l|l|l|}
\hline & & $\begin{array}{l}\text { assessment and } \\
\text { stratification.22, 23, 24 }\end{array}$ \\
5 - Lines 322-324 are clumsy \\
and should be re-written & Re-written as suggested. & $\begin{array}{l}\text { We designed and developed } \\
\text { the OSFI starting from the } \\
\text { concept of frailty and its } \\
\text { different applications for pre- } \\
\text { operative risk assessment in } \\
\text { general and geriatric surgery. }\end{array}$ \\
\hline
\end{tabular}


We developed a novel Ocular Surface Frailty Index and we internally validated that as the only significant predictor of post-operative ocular surface symptoms onset in asymptomatic patients undergoing cataract surgery. 


\section{TITLE PAGE}

2 The Ocular Surface Frailty Index as a predictor of ocular surface symptoms onset

3 after cataract surgery

4

5 Edoardo Villani MD, ${ }^{1}$ Luca Marelli MD, ${ }^{1}$ Francesco Bonsignore OD, ${ }^{1}$ Stefano Lucentini

6 MD, ${ }^{1}$ Saverio Luccarelli MD, ${ }^{1}$ Matteo Sacchi MD, ${ }^{1}$ Massimiliano Serafino MD, ${ }^{1}$ Paolo Nucci

$7 \quad M D^{1}$

8

1. Department of Clinical Sciences and Community Health, University of Milan. Eye Clinic San Giuseppe Hospital, IRCCS Multimedica, Milan, Italy

11

12

Correspondence:

13

Edoardo Villani, Eye Clinic San Giuseppe Hospital, via San Vittore 12, 20123, Milan, Italy

Edoardo.villani@unimi.it

15

Financial Support: None

17

No conflicting relationship exists for any author

19

Short title: OSFI as a predictor of cataract surgery-related DED symptoms onset

21 


\section{ABSTRACT}

Purpose: The identification of healthy subjects more susceptible to develop postsurgical ocular surface symptoms is still an unmet need. We performed this study to build a new Ocular Surface Frailty Index (OSFI) and to assess its predictive value for dry eye (DED) symptoms onset after cataract surgery.

Design: Single-centre, observational, longitudinal study.

Participants: We screened 405 consecutive patients scheduled for phacoemulsification for age-related cataract. 284 eyes of 284 patients without preoperative DED symptoms who underwent uneventful cataract surgery were included in the analysis.

Methods: Borrowing a concept from geriatric surgery and following a previously validated procedure, we built a tool to assess ocular surface frailty. Starting from a preliminary list of 19 potential items, the final OSFI, including 10 "deficits in ocular surface health and/or factors potentially able to affect it”, was developed by a stepwise approach. Pre-operative OSFI was calculated for each enrolled patient and diagnostic tests for DED were performed (following the TFOS DEWS II recommendations) at the screening visit and 1 week (V1), 1 month (V2), and 3 months (V3) after surgery. We evaluated OSFI predictivity for the presence of DED symptoms at V2 AND/OR V3.

Main Outcome Measures: The rate of ocular surface symptoms at V2 AND/OR V3.

Results: Our patients' OSFI score ranged from 0 to 0.666 , with a median value of $0.200(0.133-0.266)$. The percentage of patients with post-surgical ocular surface symptoms was $17 \%$. Using an OSFI cut-off of 0.300 , we identified a small group (19\% of the asymptomatic subjects) of patients with frail ocular surfaces, who had a significantly higher risk to develop post-surgical DED symptoms (50.0\% vs $9.6 \% ; P<0.001, \mathrm{X} 2$ test). Logistic regression analysis showed that $\mathrm{OSF} I \geq 0.3$ (but not age, gender or any preoperative sign) was a good predictor of ocular surface symptoms onset (odds ratio (OR) 
$53=9.45 ; 95 \% \mathrm{Cl}(4.74-18.82)$. Regression was still significant when performed on 200

54 bootstrapped samples.

55 Conclusions: The OSFI can be easily and quickly calculated using non-invasive 56 and low-tech procedures and it showed to be predictive of post-operative ocular surface 57 symptoms onset. This novel tool might allow cataract surgeons to perform a useful pre58 operative personalized risk assessment.

59

60

61

62

63

64

65

66

67

68

69

70

71

72

73

74

75

76

77 
Age related cataract surgery with phacoemulsification and intraocular lens (IOL) implantation is the most commonly performed ophthalmic surgery in adults of developed countries $^{1}$. This constantly improving procedure leads to a marked improvement of patients' vision and quality of life, even when performed in eyes with concomitant diseases. $^{1}$

Dry Eye Disease (DED), as well, represents a heavy social and economic burden, especially in developed countries, ${ }^{2}$ and its prevalence is expected to increase, considering the global aging of population ${ }^{3}$.

Cataract and DED are commonly associated in elderly. ${ }^{4}$ Moreover, phacoemulsification can independently transiently induce or exacerbate DED symptoms, which are a major complaint in the early post-operative period, 4,5 with a peak in the first weeks after surgery, usually followed by gradual improvement. 6,7

At present, there is a growing consensus on the multifactorial origin of the cataract surgery-related DED symptoms and on the importance of a careful peri-operative management of the ocular surface, especially in patients with pre-operative symptoms. ${ }^{4,8}$ However, the identification of healthy asymptomatic subjects more susceptible to develop post-operative ocular surface symptoms is still an unmet need.

Frailty, or frailty syndrome, may be conceptually defined as a clinically recognizable state of older adults with increased vulnerability to stressors, resulting from age-associated declines in physiologic reserve and function across multiple organ systems, such that the ability to cope with stressors is compromised, leading to adverse health outcome. ${ }^{9}$ This condition is currently considered as an emerging public health problem ${ }^{10}$ and its importance has been recently highlighted by the World Health Organization in the "World Report on Ageing and Health". ${ }^{11}$ There is large consensus on the use of Frailty Index $(\mathrm{FI})$ as a frailty assessment tool. This score, which can be developed following a previously published standard procedure, ${ }^{12}$ has 
been validated as a predictor of surgical adverse outcomes in several fields, ${ }^{13}$ including otolaryngology ${ }^{14}$, ambulatory general surgery ${ }^{15}$, and cardiac surgery. ${ }^{16}$ Interestingly, Esses GJ et al. recently examined the relationship between frailty and postsurgical pain in older adults, concluding that frailty was an independent predictor of intrusive pain at 3 months following surgery. ${ }^{17}$ The authors speculated that the assessment of preoperative frailty might become a tool for the healthcare provider to focus attention on the individual patient's needs and to identify patients with high postsurgical risk to develop symptoms.

We hypothesized that the concept of frailty might be applied to the ocular surface morphofunctional unit of patients undergoing age-related cataract surgery. The purpose of this study was to build a new Ocular Surface Frailty Index (OSFI) and to assess its predictive value for the onset of cataract surgery-related ocular surface symptoms in the early postoperative period.

\section{Methods}

This single-centre, observational, longitudinal study included a large convenient sample of patients without DED symptoms who underwent uneventful cataract surgery at the San Giuseppe Eye Clinic-University Hospital of Milan during a period of four months, from March to June 2018.

We screened 405 consecutive patients scheduled for sutureless small-incision cataract surgery with phacoemulsification and posterior chamber monofocal IOL implantation. Inclusion criteria were diagnosis of age-related cataract and willingness to participate in the study and to subscribe the informed consent. Patients with pre-operative DED symptoms, defined as Ocular Surface Disease Index (OSDI) $\geq 13,{ }^{18}$ were excluded. Patients with DED signs without symptoms were included.DED signs without symptoms were not considered as exclusion criteria. ${ }^{19}$ 
We included 284 out of 405 patients. 114 patients were excluded before surgery (70 because of pre-operative DED symptoms, 14 of which without DED diagnostic signs, and 44 refused to participate) and 7 patients were excluded after surgery ( 2 because of intraoperative complications - posterior capsule rupture requiring anterior vitrectomy - and 5 were lost to follow-up).

The study protocol contemplated 4 visits: screening/baseline visit (V0, $7 \pm 3$ days before surgery), aimed to verify the respect of inclusion and exclusion criteria and to calculate the OSFI score; $1^{\circ}$ follow up (V1, $7 \pm 2$ days after surgery), $2^{\circ}$ follow up (V2, $30 \pm 7$ days after surgery), and $3^{\circ}$ follow up (V3, 90 \pm 7 days after surgery ) visits, all aimed to verify the respect of inclusion and exclusion criteria, the onset of ocular surface symptoms and the presence of DED. Table 1, available at www.aaojournal.org, shows the procedures scheduled for each visit.

The study adhered to the tenets of the Declaration of Helsinki, it was approved by the local $\mathrm{IRB}$, and written informed consent was obtained by each patient.

\section{Procedures}

Each patient completed a questionnaire regarding on his/her medical history, including information on ocular and systemic diseases, topical and systemic therapies, computer usage, and contact lens wear, and an Ocular Surface Disease Index (OSDI) questionnaire. ${ }^{18}$

The questionnaire specifically investigated if the patient had previous diagnosis of diabetes, rosacea, connective tissue diseases, thyroid malfunction, affective, somatoform disorders, anxiety and depression, the use of systemic and topical medications, computer usage $>4$ hours/day for at least 5 days/week, contact lens wear $>4$ hours/day for at least 5 days/week. Each patients completed the questionnaire autonomously and then discussed that with the investigator. 
Clinical procedures for ocular surface examination included, when appropriate (Table 1, available at www.aaojournal.org), measurement and quantification of: tear film osmolarity (by TearLab, TearLab Corporation, Escondido, CA), ${ }^{19}$ fluorescein tear film break-up time (T-BUT),${ }^{19}$ fluorescein ocular surface staining, ${ }^{19}$ meibomian glands expressibility (grade 03), ${ }^{19,20}$ lid parallel conjunctival folds (LIPCOF; grade 0-3), ${ }^{19,21}$ and tear secrection (Schirmer test without anesthesia, performed at least 15 minutes after the end of the previous procedure). ${ }^{19}$

All the procedures were performed following the recommendations of the Tear Film and Ocular Surface Society Dry Eye Workshop II (TFOS DEWS II) Diagnostic Methodology report, ${ }^{19}$ and the test sequence was arranged in order to best preserve their integrity. ${ }^{19}$

\section{Ocular surface symptoms onset definition}

Our main outcome was the onset of cataract surgery-related ocular surface symptoms, which was assessed using the OSDI questionnaire. We defined this condition as (OSDI Vn 213) AND (OSDI Vn - OSDI baseline $\geq 4)^{18,22}$ at V2 AND/OR V3.

\section{DED diagnosis}

Our secondary outcome was the presence of DED. According to the TFOS DEWS II

Diagnostic Methodology report, DED was diagnosed in presence of a "screening"

OSDI $\geq 13$ plus at least 1 of the following "homeostasis markers": tear film osmolarity $\geq 308 \mathrm{mOsm} / \mathrm{L}$ or interocular difference $>8 \mathrm{mOsm} / \mathrm{L}, \mathrm{T}-\mathrm{BUT}<10$ seconds, and positive corneal, conjunctival or lid margin staining. ${ }^{19}$

\section{OSFI development}

We borrowed the concept of frailty and we built the OSFI following and adapting the

"standard procedure for creating a frailty index" previously described and validated by

Searle SD et al. ${ }^{12}$

Briefly, OSFI is based on a count of "deficits in ocular surface health and/or factors potentially able to affect it”. Each investigator independently proposed a list of 30 
"candidate items". Agreement on the preliminary list of 19 items was then obtained through open discussion, paying attention to include variables which were associated with ocular surface health status, whose prevalence generally increase with age, and which don't saturate too early (for instance, presbyopia is nearly universal by age 55 , saturating too early to be included in this type of frailty index $)^{12}$ paying attention to include variables which were associated with ocular surface health status, whose prevalence generally increases with age, and which doesn't saturate too early. Moreover, when considering the candidate deficits as a group, we selected the preliminary list trying to cover a range of systems and mechanisms having an impact on the ocular surface health. Finally we prioritized variables easily, quickly and cheaply assessable.

All binary variables were recorded using the convention that " 0 " indicates the absence of the deficit, and " 1 " the presence of it. Continuous and ordinal variables were graded into a score between "0" and "1", after testing different strategies for their categorization. The index is then expressed as: positive items/total number of assessed items.

The preliminary OSFI composition is reported in Table 2 (available at www.aaojournal.org).

In order to optimize the OSFI composition, we performed Spearman correlation and univariate logistic analysis to assess associations between each preliminary OSFI item and the development of post-surgical DED symptoms. We excluded the items showing a negative correlation coefficient and then we adopted a stepwise approach, progressively excluding the items with the weakest association for the outcome, defined as the highest $P$ value in the regression model. At each step, OSFI score was re-calculated and its predictive value for the main outcome was re-tested on a bootstrap of 200 samples. This process was stopped when, moving from 10 to 9 items, the OSFI predictive value decreased, showing an higher $\mathrm{P}$ value of the regression analysis (Table 3). 
We tested different strategies for continuous and ordinal items categorization, selecting the ones providing the best OSFI predictive value.

The final OSFI composition, including 10 items, is reported in Table 4.

We assessed OSFI Inter-observer reproducibility on an external group of 20 patients undergoing cataract surgery. Two investigators (EV, FB) independently examined the patients and quantified the OSFI score in 2 consecutive days.

\section{Statistical analysis}

In descriptive statistics, normally distributed variables were presented as mean \pm standard deviation (SD), non-normally distributed variables were presented as median (interquartile range), and categorical variables as number (percentage).

Comparisons between groups were made using Mann-Whitney $U$ test for continuous variables, dependent on distribution, and $x^{2}$ test for categorical variables.

Correlations between continuous variables were tested by Spearman's correlation coefficient.

Receiver Operating Characteristic (ROC) curve analysis was used to identify the optimal OSFI cut-off point for development of post-surgical DED symptoms.

Multivariable logistic regression analysis was performed in a standard stepwise approach, with inclusion of significant variables $(P<0.05)$ after univariable regression.

Bootstrapping was performed on 200 samples, with simple sampling strategy and $95 \% \mathrm{Cl}$. Inter-observer reproducibility was assessed by Interclass Correlation Coefficient (ICC). The minimum criterion for tests of significance was $\mathrm{P}<0.05$.

Statistical analysis was conducted using a commercial software (SPSS for Windows, v. 20; SPSS Sciences, Chicago, IL).

\section{Results}

The mean age of the 284 included patients was $74.53 \pm 8.16$ years; 105 (37\%) were males. At baseline, given the exclusion criteria, none of the included patients showed DED 
symptoms (OSDI $\geq 13)$. However, 206 patients $(72.5 \%)$ had at least one DED sign without symptoms. Specifically, positive values of tear osmolarity, T-BUT and ocular surface fluorescein staining ${ }^{19}$ were found in 64 (22.5\%), 185 (65.1\%), and 53 (18.7\%) patients, respectively.

The overall cumulative percentage of patients showing ocular surface symptoms at V2 AND/OR V3 was $17 \%$ (48 of 284 ), Table 5 . Of these patients, 36 (75\%) fulfilled the DED diagnostic criteria in at least 1 follow-up visit.

Univariate logistic regression showed that age and gender had no association with DED symptoms onset after cataract surgery $(\mathrm{OR}=0.98$ (0.95-1.02), $\mathrm{P}=0.38$ and $\mathrm{OR}=1.26(0.65$ 2.41), $P=0.49$, respectively)..

Moreover, no baseline DED sign showed to be a significant predictor for post-operative onset of symptoms $(\mathrm{P}=0.25, \mathrm{P}=0.10$, and $\mathrm{P}=0.44$ for osmolarity, $\mathrm{T}$-BUT, and staining, respectively).

Our patients' OSFI score ranged from 0 to 0.666 , with a median value of 0.200 (0.133$0.266)$.

The prevalence of each OSFI item is shown in Figure 1 (available at www.aaojournal.org) and in Table 3; the 5 most common components were reduced T-BUT (185 [65\%]), computer usage (83 [29\%]), psychiatric conditions (80 [28\%]), LIPCOF=3 (54 [19\%]), and MGs expressibility=3 (41 [14\%]).

The twenty patients assessed for inter-observer reproducibility showed almost perfect agreement $(I C C=0.93)$ in OSFI score quantification between EV $(0.216[0.162-0.370])$ and FB (0.225 [0.162-0.362]).

OSFI score of patients who showed DED symptoms at V2 AND/OR V3 (0.300 [0.233$0.399])$ was significantly higher of the score $(0.166$ [0.116-0.249]) of patients without postsurgical symptoms $(P<0.001$, Mann-Whitney $U$ test $)$. In order to support the OSFI construct validity, we compared the rate of post-operative 
symptoms of patients with the lowest OSFI values (10th percentile) vs the rate of symptoms of patients with the highest OSFI values (90th percentile): 0 vs 18/28 (64\%); $\mathrm{P}<0.001, \mathrm{X}^{2}$ test. Moreover, we compared OSFI values of patients with the lowest $\max$ post-operative OSDI values (10th percentile) vs OSFI values of patients with the highest max post-operative OSDI values (90th percentile): $0.183(0.108-0.249)$ vs 0.333 (0.2330.433); $P<0.001$, Mann-Whitney U test.

In a logistic regression model, none of the OSFI components showed to be a significant predictor of DED symptoms' onset (Table 3).

On ROC curve analysis, the area under the curve was 0.821 . OSFI value of 0.241 , with sensitivity of $74 \%$ and specificity of $77 \%$, showed the highest Youden index. However, setting the specificity to $90 \%$, we found a cut-off of 0.3 (sensitivity $=53 \%$ ) (Figure 2 ). In our population, we found 230 (81\%) patients with OSFI<0.3 and $54(19 \%)$ patients with frail ocular surface (OSFI $\geq 0.3)$; figure 3 .

The rate of post-operative DED symptoms was significantly higher in patients with frail ocular surface ( 27 of $54 ; 50 \%$ ) than in patients with robust ocular surface (22 of $230 ; 9 \%$ ); $P<0.001, X^{2}$ test.

Logistic regression analysis showed that $O S F I \geq 0.3$ was a good predictor of ocular surface symptoms onset (odds ratio $(\mathrm{OR})=9.45 ; 95 \% \mathrm{Cl}(4.74-18.82)$. $\mathrm{P}<0.001)$. No significant changes were found after adjusting the analysis for age and gender (OR=9.35 (4.6818.68), $P<0.001)$.

Bootstrapping 200 samples, $\mathrm{Cl}$ of this logistic analysis remained above 1.0 (1.58-2.99); $\mathrm{P}<0.01$

OSFI $\geq 0.3$ was a significant predictor also for the development of post-surgical DED (defined as symptoms + at least 1 sign): $\mathrm{OR}=3.54 ; 95 \% \mathrm{Cl}(1.73-7.21) ; \mathrm{P}<0.001$.

\section{Discussion}

Even if the advanced age can carry increased risk of post-surgical adverse events, 
the chronological age is not suitable to be used as a tool for pre-operative risk

assessment and stratification.22, 23, 24 Geriatric surgery taught us that advanced age can earry increased risk of adverse events, including mortality and morbidity, after surgery.23 However, the scientific literature clearly showed that the chronological age should not be used as a tool for pre-operative risk assessment and stratification. ${ }^{23,24}$

The concept of frailty arises from the need to identify those individual with decreased functional capacity, and therefore to identify patients with an increased risk of post-surgical negative events. ${ }^{11,23,24} \mathrm{~A}$ large growing body of literature shows the importance of measuring frailty before performing several different types of surgeries and the Frailty Indexes, although not yet optimized and adequately standardized, are reported to be one of the most prominent tools for patients' risk stratification. ${ }^{23,24}$ Age-related cataract surgery is a very common geriatric surgery with no (or maybe with beneficial) impact on mortality and systemic morbidity, ${ }^{25}$ able to clearly improve visual function and quality of life, ${ }^{26}$ but associated with a relevant risk of inducing or worsening ocular surface symptoms. ${ }^{4}$ Several studies focused on the multifactorial pathophysiological mechanisms underlying cataract surgery-induced DED, including the use of topical anesthetics and exposure desiccation, possible light toxicity from the operating microscope, nerve transection, elevation of inflammatory factors, goblet cell loss, and meibomian gland dysfunction, and on the most effective therapeutic approaches for this condition. ${ }^{4}$ However, at present, there are no validated tools to be used for stratifying the risk of a clinically relevant negative impact of cataract surgery on the ocular surface health. Previous studies, with heterogeneous designs, populations, and methodologies, explored the predictive value of several peri-operative parameters (e.g. age, diabetes, socio-economic status, site of incision, microscope light exposure time, ...). ${ }^{27-29}$ These reports showed conflicting results and failed to provide consistent evidence ${ }^{3}$ supporting the use of any of these parameters for risk assessment. Our results confirmed this issue, 
showing that no baseline personal or clinical data would be a significant predictor of the development of post-surgical symptoms.

The TFOS DEWS II latrogenic report generically stated that "even in the absence of DED, ocular surface disease should be managed before cataract surgery". ${ }^{4}$ This recommendation highlights the peculiar challenge represented by the relevant percentage ( $17 \%$ in our study population) of asymptomatic patients developing ocular surface symptoms after surgery.

\section{We designed and developed the OSFI starting from the concept of frailty and its different} applications for pre-operative risk assessment in general and geriatric surgery.Borrowing from researches on general and geriatric surgery the concept of frailty and the procedure to develop a tool for its quantification, and adapting them to the ocular surface, we built the OSFI. This novel tool, simultaneously evaluating several different potential mechanisms and markers of "deficits in ocular surface health", might allow performing effective preoperative risk stratification. The identification of non-DED patients more susceptible to develop surgery-related ocular surface symptoms and DED might be useful to improve patient-doctor communication, to adjust patients' expectations, reducing the subsequent dissatisfaction and to plan a more personalized and successful management of the patients' ocular surface.

We included in the preliminary OSFI 19 items, related to medical history and clinical findings, that we considered being potentially important "deficits in ocular surface health or factors potentially able to affect it". Most of these items have been classified by the TFOS DEWS II Epidemiology Report as "consistent" or "probable" risk factors for DED. ${ }^{3}$

Moreover, we paid attention to select items suitable to be easily, quickly and cheaply assessed in the context of a general ophthalmic clinical setting/ cataract service. For this reason, we avoided to include in the OSFI data requiring high-tech, time-consuming, expensive exams or procedures broadly used just in cornea/ocular surface reference 
centers (e.g. OCT meniscometry, tear film osmolarity, infrared meibography, ...). In order to improve both the OSFI predictive value and clinical utility, we excluded from the preliminary index the items showing negative and weak positive correlations with the outcome. This process led to the definition of the final OSFI, including 10 items.

Nevertheless, OSFI quantification would require adding some extra minutes to the preoperative examination of patients and this might limit its spread and use in daily clinical practice. However, given the relevance of the potential post-operative issue ${ }^{4,8}$ this seems to be a reasonable effort to be done in order to perform an effective risk assessment. Our selection of OSFI components is somewhat arbitrary and might be refined through future studies. However, this issue is inherent in all the processes aimed to build new tools for frailty assessment and, interestingly, previous studies showed that, if the selection criteria are properly applied, the results are insensitive to the precise composition of the index. ${ }^{12,30}$

The OSFI cut-off of 0.3 allowed us to identify a small group (19\% of the asymptomatic subjects) of patients with a frail ocular surface morpho-functional unit, at high risk to develop post-operative ocular surface symptoms. These patients might be managed with a personalized approach, both before and after surgery, including not only tailored therapies but also a peculiar communication effort.

In order to validate the OSFI score, we considered its inter-observer reproducibility, and content and construct validity.

Reproducibility was tested in the most challenging conditions, with 2 independent investigators quantifying the Index in 2 different days, and it showed an almost perfect inter-observer agreement.

Content validity of the preliminary OSFI was partly assured by its development procedure, based on agreement among experts (the investigators) working on updated evidences on the topic, recently selected by the TFOS DEWS II panel. ${ }^{3}$ Content validity of the final OSFI 
was assessed arranging in a matrix 4 key etiologic domains of DED ${ }^{31}$ and the OSFI items (Table 6, available at www.aaojournal.org). The final OSFI items seem to be welldistributed and related to tear film instability, ocular surface inflammation, neuro-sensory abnormalities, and ocular surface epithelial damage. Interestingly, the stepwise process excluded ocular surface fluorescein staining and Schirmer test from the final OSFI. Patients with severe epitheliopathy and/or severely reduced tears secretion are generally symptomatic and they were excluded at the screening visit. About mild epitheliopathy and/or hypersecretion, these results might further confirm the well-known lack of correlation between DED signs and symptoms. ${ }^{32}$ Moreover, a proportion of normal corneas, especially after the age of 50 , show punctate fluorescein uptake. ${ }^{33}$

This is the first paper theorizing and proposing the concept of ocular surface frailty, and developing a tool for its assessment. In the absence of other reference tools for ocular surface frailty quantification and in order to support the OSFI construct validity, we demonstrated that the rate of post-operative symptoms of the patients with the lowest OSFI values (10th percentile) was 0 and the rate of symptoms of the patients with the highest OSFI values (90th percentile) was $64 \%$. We also demonstrated that the patients with the highest max post-operative OSDI values (90th percentile) had significantly higher OSFI values than the patients with the lowest max post-operative OSDI values (10th percentile).

We did not assess OSFI internal consistency. The presence of strong correlations among the items is important in scales including items tapping a single domain or attribute. In indexes like OSFI, the items are not manifestations of an underlying construct (effect indicators) but the items themselves define the construct (causal indicators). In this type of tools, the items may or may not covariate, irrespective of their relationship with the construct. $^{34}$ Finally, we supported the internal validation of OSFI performing the stepwise process for 
the final index definition and the logistic regression analysis of the index cut-off predictivity on a bootstrap of 200 samples.

External validation, however, remains the gold standard to assess the true validity of OSFI when applied to other patient samples, and this will be our next step. External validation will have to be performed on a larger, multi-centric, more heterogeneous population, including patients undergoing cataract surgery with multifocal IOL implantation. This latter point is of particular importance since these patients have especially high pre-operative expectations and ocular surface symptoms may significantly affect patients' perception of the surgery's outcome.

This study has other limitations, including the short follow-up. However, this research was focused on cataract surgery-related DED symptoms onset, reported mainly in the first weeks after surgery, ${ }^{6,7}$ and not on their course.

In conclusion, we built a novel tool in order to assess the frailty of the ocular surface of patients undergoing cataract surgery. The OSFI, which showed to be the only significant predictor of ocular surface symptoms onset in our patients, will have to be validated in different and larger populations. This tool might be refined and maybe adapted to the reality of the different Countries, but we think that this type of novel application of the concept of frailty could contribute to improve our capabilities to have an effective and personalized approach to the ocular surface of patients undergoing cataract surgery. 


\section{References}

415 1. Lam D, Rao SK, Ratra V, et al. Cataract. Nat Rev Dis Primers. 2015;1:15014.

$416 \quad$ 2. Clayton JA. Dry Eye. N Engl J Med. 2018;378:2212-2223.

417 3. Stapleton F, Alves M, Bunya VY, et al. TFOS DEWS II Epidemiology Report. Ocul $418 \quad$ Surf. 2017;15:334-365.

419 4. Gomes JAP, Azar DT, Baudouin C, et al. TFOS DEWS II iatrogenic report. Ocul $420 \quad$ Surf. $2017 ; 15: 511-538$.

421 5. Szakáts I, Sebestyén M, Tóth É PG. Dry Eye Symptoms, Patient-Reported Visual Surgery. Curr Eye Res. 42:832-8365.

6. Cetinkaya S, Mestan E, Acir NO, Cetinkaya YF, Dadaci Z YH. The course of dry eye after phacoemulsification surgery. BMC Ophthalmol. 2015;5:68.

7. Kasetsuwan N, Satitpitakul V, Changul T, Jariyakosol S. Incidence and pattern of dry eye after cataract surgery. PLoS One. 2013;8:e78657.

8. Choi YJ, Park SY, Jun I, et al. Perioperative Ocular Parameters Associated With Persistent Dry Eye Symptoms After Cataract Surgery. Cornea. 2018;37:734-739.

9. Chen X, Mao G, Leng SX. Frailty syndrome: An overview. Clin Interv Aging. 2014;9:433-441.

10. Cesari M, Prince M, Thiyagarajan JA, et al. Frailty: An Emerging Public Health Priority. J Am Med Dir Assoc. 2016;17:188-92.

11. World Health Organization. World Report on Ageing and Health. http://apps.who.int/iris/bitstream/handle/10665/186463/9789240694811_eng.pdf;jse ssionid=14AE727B59D8E8C68C4EA7747A89FB15? sequence $=1 ; 2015$. Accessed Jan 19, 2019.

12. Searle SD, Mitnitski A, Gahbauer EA, Gill TM, Rockwood K. A standard procedure 
for creating a frailty index. BMC Geriatr. 2008;8.

13. Darvall JN, Gregorevic KJ, Story DA, Hubbard RE, Lim WK. Frailty indexes in perioperative and critical care: A systematic review. Arch Gerontol Geriatr. 2018;79:88-96.

14. Abt NB, Richmon JD, Koch WM, Eisele DW, Agrawal N. Assessment of the predictive value of the modified frailty index for Clavien-Dindo grade IV critical care complications in major head and neck cancer operations. JAMA Otolaryngol - Head Neck Surg. 2016;142:658-664.

15. Seib $\mathrm{CD}$, Rochefort $\mathrm{H}$, Chomsky-Higgins $\mathrm{K}$, et al. Association of patient frailty with increased morbidity after common ambulatory general surgery operations. JAMA Surg. 2018;153:160-168.

16. Shi S, Afilalo J, Lipsitz LA, et al. Frailty Phenotype and Deficit Accumulation Frailty Index in Predicting Recovery After Transcatheter and Surgical Aortic Valve Replacement. J Gerontol A Biol Sci Med Sci. 2018 Aug 25. doi:10.1093/gerona/gly196. [Epub ahead of print]

17. Esses GJ, Liu X, Lin HM, Khelemsky Y, Deiner S. Preoperative frailty and its association with postsurgical pain in an older patient cohort. Reg Anesth Pain Med. 2019 May 6. pii: rapm-2018-100247.

18. Schiffman RM, Christianson MD, Jacobsen G, Hirsch JD RB. Reliability and validity of the ocular surface disease index. Arch Ophthalmol. 2000;118:615-21.

19. Wolffsohn JS, Arita R, Chalmers R, et al. TFOS DEWS II Diagnostic Methodology report. Ocul Surf. 2017;15:539-574.

20. Geerling G, Tauber J, Baudouin C, et al. The international workshop on meibomian gland dysfunction: report of the subcommittee on management and treatment of meibomian gland dysfunction. Invest Ophthalmol Vis Sci 2011;52:2050e64.

21. Pult $H$, Purslow $C$, Murphy PJ. The relationship between clinical signs and dry eye 
symptoms. Eye (Lond) 2011;25:502e10.

22. Miller KL, Walt JG, Mink DR, et al. Minimal clinically important difference for the ocular surface disease index. Arch Ophthalmol. 2010;128:94-101.

23. Lin HS, Watts JN, Peel NM, Hubbard RE. Frailty and post-operative outcomes in older surgical patients: a systematic review. BMC Geriatr. 2016;16:157.

24. Buigues C, Juarros-Folgado P, Fernández-Garrido J, Navarro-Martínez R, Cauli O. Frailty syndrome and pre-operative risk evaluation: A systematic review. Arch Gerontol Geriatr. 2015;61:309-21.

25. Song E, Sun $\mathrm{H}, \mathrm{Xu} \mathrm{Y}, \mathrm{Ma} \mathrm{Y}$, Zhu H, Pan CW. Age-related cataract, cataract surgery and subsequent mortality: a systematic review and meta-analysis. PLoS One. 2014;9:e112054.

26. Shekhawat NS, Stock MV, Baze EF, et al. Impact of First Eye versus Second Eye Cataract Surgery on Visual Function and Quality of Life. Ophthalmology. 2017;124:1496-1503.

27. Jiang D, Xiao X, Fu T, Mashaghi A, Liu Q, Hong J. Transient Tear Film Dysfunction after Cataract Surgery in Diabetic Patients. PLoS One. 2016;11:e0146752.

28. Park $\mathrm{Y}, \mathrm{Hwang} \mathrm{H}$ Bin, Kim HS. Observation of influence of cataract surgery on the ocular surface. PLoS One. 2016;11:e0152460.

29. Kohli P, Arya SK, Raj A, Handa U. Changes in ocular surface status after phacoemulsification in patients with senile cataract. Int Ophthalmol. 2018 Jun 20. doi: 10.1007/s10792-018-0953-8. [Epub ahead of print]

30. Rockwood K, Andrew M, Mitnitski A. A Comparison of two approaches to measuring frailty in elderly people. J Gerontol A Biol Sci Med Sci 2007, 62A:738-743.

31. Craig JP, Nichols KK, Akpek EK, et al. TFOS DEWS II Definition and Classification Report. Ocul Surf. 2017;15:276-283.

32. Sullivan BD, Crews LA, Messmer EM, et al. Correlations between commonly used 
objective signs and symptoms for the diagnosis of dry eye disease: clinical implications. Acta Ophthalmol. 2014;92:161-6.

33. Bron AJ, Argüeso P, Irkec M, Bright FV. Clinical staining of the ocular surface: mechanisms and interpretations. Prog Retin Eye Res. 2015;44:36-61.

34. Streiner DL. Being inconsistent about consistency: when coefficient alpha does and doesn't matter. J Pers Assess. 2003;80:217-22

\section{Figure legends}

Figure 1. Population prevalence of OSFI components.

The prevalence of OSFI components ranged from $65 \%$ for BUT $<10$ seconds to $0.7 \%$ for connective tissue diseases. T-BUT: fluorescein tear film break-up time; LIPCOF: lid parallel conjunctival folds; MGs: Meibomian glands; OSDI: Ocular Surface Disease Index.

\section{Figure 2. Receiver Operating Curve Analysis for post-operative DED symptoms} onset.

The Area Under the Curve (AUC) was 0.821. OSFI score of 0.241 showed the highest, with sensitivity of $74 \%$ and specificity of $77 \%$, showed the highest Youden index. OSFI cutoff of 0.3 had sensitivity of $53 \%$ and specificity of $90 \%$. 
517 Figure 3. Distribution of Ocular Surface Frailty Index scores.

518 Higher values indicate a higher degree of frailty. 54 patients (19\%) had a frail ocular

519 surface, with OSFI $\geq 0.3$. 
1 TITLE PAGE

2 The Ocular Surface Frailty Index as a predictor of ocular surface symptoms onset

3 after cataract surgery

4

5 Edoardo Villani MD, ${ }^{1}$ Luca Marelli MD, ${ }^{1}$ Francesco Bonsignore OD, ${ }^{1}$ Stefano Lucentini

6 MD, ${ }^{1}$ Saverio Luccarelli MD, ${ }^{1}$ Matteo Sacchi MD, ${ }^{1}$ Massimiliano Serafino MD, ${ }^{1}$ Paolo Nucci

$7 \mathrm{MD}^{1}$

8

9

1. Department of Clinical Sciences and Community Health, University of Milan. Eye Clinic San Giuseppe Hospital, IRCCS Multimedica, Milan, Italy

12 Correspondence:

13 Edoardo Villani, Eye Clinic San Giuseppe Hospital, via San Vittore 12, 20123, Milan, Italy

14 Edoardo.villani@unimi.it

16 Financial Support: None

18 No conflicting relationship exists for any author 


\section{ABSTRACT}

Purpose: The identification of healthy subjects more susceptible to develop postsurgical ocular surface symptoms is still an unmet need. We performed this study to build a new Ocular Surface Frailty Index (OSFI) and to assess its predictive value for dry eye (DED) symptoms onset after cataract surgery.

Design: Single-centre, observational, longitudinal study.

Participants: We screened 405 consecutive patients scheduled for phacoemulsification for age-related cataract. 284 eyes of 284 patients without preoperative DED symptoms who underwent uneventful cataract surgery were included in the analysis.

Methods: Borrowing a concept from geriatric surgery and following a previously validated procedure, we built a tool to assess ocular surface frailty. Starting from a preliminary list of 19 potential items, the final OSFI, including 10 "deficits in ocular surface health and/or factors potentially able to affect it", was developed by a stepwise approach. Pre-operative OSFI was calculated for each enrolled patient and diagnostic tests for DED were performed (following the TFOS DEWS II recommendations) at the screening visit and 1 week (V1), 1 month (V2), and 3 months (V3) after surgery. We evaluated OSFI predictivity for the presence of DED symptoms at V2 AND/OR V3.

Main Outcome Measures: The rate of ocular surface symptoms at V2 AND/OR V3. Results: Our patients' OSFI score ranged from 0 to 0.666 , with a median value of $0.200(0.133-0.266)$. The percentage of patients with post-surgical ocular surface symptoms was $17 \%$. Using an OSFI cut-off of 0.300 , we identified a small group (19\% of the asymptomatic subjects) of patients with frail ocular surfaces, who had a significantly higher risk to develop post-surgical DED symptoms (50.0\% vs 9.6\%; P<0.001, X2 test). Logistic regression analysis showed that OSFI $\geq 0.3$ (but not age, gender or any preoperative sign) was a good predictor of ocular surface symptoms onset (odds ratio (OR) 
$53=9.45 ; 95 \% \mathrm{Cl}(4.74-18.82)$. Regression was still significant when performed on 200

54 bootstrapped samples.

55

Conclusions: The OSFI can be easily and quickly calculated using non-invasive

56 and low-tech procedures and it showed to be predictive of post-operative ocular surface

57 symptoms onset. This novel tool might allow cataract surgeons to perform a useful pre-

58 operative personalized risk assessment.

59

60

61

62

63

64

65

66

67

68

69

70

71

72

73

74

75

76

77 
Age related cataract surgery with phacoemulsification and intraocular lens (IOL) implantation is the most commonly performed ophthalmic surgery in adults of developed countries ${ }^{1}$. This constantly improving procedure leads to a marked improvement of patients' vision and quality of life, even when performed in eyes with concomitant diseases. ${ }^{1}$

Dry Eye Disease (DED), as well, represents a heavy social and economic burden, especially in developed countries, ${ }^{2}$ and its prevalence is expected to increase, considering the global aging of population ${ }^{3}$.

Cataract and DED are commonly associated in elderly. ${ }^{4}$ Moreover, phacoemulsification can independently transiently induce or exacerbate DED symptoms, which are a major complaint in the early post-operative period, ${ }^{4,5}$ with a peak in the first weeks after surgery, usually followed by gradual improvement. 6,7

At present, there is a growing consensus on the multifactorial origin of the cataract surgery-related DED symptoms and on the importance of a careful peri-operative management of the ocular surface, especially in patients with pre-operative symptoms..$^{4,8}$ However, the identification of healthy asymptomatic subjects more susceptible to develop post-operative ocular surface symptoms is still an unmet need.

Frailty, or frailty syndrome, may be conceptually defined as a clinically recognizable state of older adults with increased vulnerability to stressors, resulting from age-associated declines in physiologic reserve and function across multiple organ systems, such that the ability to cope with stressors is compromised, leading to adverse health outcome. ${ }^{9}$ This condition is currently considered as an emerging public health problem ${ }^{10}$ and its importance has been recently highlighted by the World Health Organization in the "World Report on Ageing and Health". ${ }^{11}$

There is large consensus on the use of Frailty Index (FI) as a frailty assessment tool. This score, which can be developed following a previously published standard procedure, ${ }^{12}$ has 
104 been validated as a predictor of surgical adverse outcomes in several fields, ${ }^{13}$ including otolaryngology ${ }^{14}$, ambulatory general surgery ${ }^{15}$, and cardiac surgery. ${ }^{16}$ Interestingly, Esses GJ et al. recently examined the relationship between frailty and postsurgical pain in older adults, concluding that frailty was an independent predictor of intrusive pain at 3 months following surgery. ${ }^{17}$ The authors speculated that the assessment of preoperative frailty might become a tool for the healthcare provider to focus attention on the individual patient's needs and to identify patients with high postsurgical

111 risk to develop symptoms.

112 We hypothesized that the concept of frailty might be applied to the ocular surface morpho113 functional unit of patients undergoing age-related cataract surgery. The purpose of this 114 study was to build a new Ocular Surface Frailty Index (OSFI) and to assess its predictive 115 value for the onset of cataract surgery-related ocular surface symptoms in the early post116 operative period.

\section{Methods}

118 This single-centre, observational, longitudinal study included a large convenient sample of 119 patients without DED symptoms who underwent uneventful cataract surgery at the San 120 Giuseppe Eye Clinic-University Hospital of Milan during a period of four months, from 121 March to June 2018.

122 We screened 405 consecutive patients scheduled for sutureless small-incision cataract 123 surgery with phacoemulsification and posterior chamber monofocal IOL implantation.

124 Inclusion criteria were diagnosis of age-related cataract and willingness to participate in 125 the study and to subscribe the informed consent. Patients with pre-operative DED 126 symptoms, defined as Ocular Surface Disease Index (OSDI) $\geq 13,{ }^{18}$ were excluded. 127 Patients with DED signs without symptoms were included. ${ }^{19}$

128 We included 284 out of 405 patients. 114 patients were excluded before surgery (70 129 because of pre-operative DED symptoms, 14 of which without DED diagnostic signs, and 
44 refused to participate) and 7 patients were excluded after surgery ( 2 because of intraoperative complications - posterior capsule rupture requiring anterior vitrectomy - and 5 were lost to follow-up).

The study protocol contemplated 4 visits: screening/baseline visit (V0, $7 \pm 3$ days before surgery), aimed to verify the respect of inclusion and exclusion criteria and to calculate the OSFI score; $1^{\circ}$ follow up ( $\mathrm{V} 1,7 \pm 2$ days after surgery), $2^{\circ}$ follow up (V2, $30 \pm 7$ days after surgery), and $3^{\circ}$ follow up ( $\mathrm{V} 3,90 \pm 7$ days after surgery ) visits, all aimed to verify the respect of inclusion and exclusion criteria, the onset of ocular surface symptoms and the presence of DED. Table 1, available at www.aaojournal.org, shows the procedures scheduled for each visit.

The study adhered to the tenets of the Declaration of Helsinki, it was approved by the local IRB, and written informed consent was obtained by each patient.

\section{Procedures}

Each patient completed a questionnaire regarding his/her medical history, including information on ocular and systemic diseases, topical and systemic therapies, computer usage, and contact lens wear, and an Ocular Surface Disease Index (OSDI) questionnaire. $^{18}$

The questionnaire specifically investigated if the patient had previous diagnosis of diabetes, rosacea, connective tissue diseases, thyroid malfunction, affective, somatoform disorders, anxiety and depression, the use of systemic and topical medications, computer usage $>4$ hours/day for at least 5 days/week, contact lens wear $>4$ hours/day for at least 5 days/week. Each patients completed the questionnaire autonomously and then discussed that with the investigator.

Clinical procedures for ocular surface examination included, when appropriate (Table 1, available at www.aaojournal.org), measurement and quantification of: tear film osmolarity (by TearLab, TearLab Corporation, Escondido, CA) ${ }^{19}$ fluorescein tear film break-up time 
156 (T-BUT), ${ }^{19}$ fluorescein ocular surface staining, ${ }^{19}$ meibomian glands expressibility (grade 0 3), ${ }^{19,20}$ lid parallel conjunctival folds (LIPCOF; grade 0-3), ${ }^{19,21}$ and tear secrection

158 (Schirmer test without anesthesia, performed at least 15 minutes after the end of the 159 previous procedure).$^{19}$

160 All the procedures were performed following the recommendations of the Tear Film and 161 Ocular Surface Society Dry Eye Workshop II (TFOS DEWS II) Diagnostic Methodology 162 report, ${ }^{19}$ and the test sequence was arranged in order to best preserve their integrity. ${ }^{19}$

\section{Ocular surface symptoms onset definition}

164 Our main outcome was the onset of cataract surgery-related ocular surface symptoms, 165 which was assessed using the OSDI questionnaire. We defined this condition as (OSDI Vn $166 \geq 13)$ AND (OSDI Vn - OSDI baseline $\geq 4)^{18,22}$ at V2 AND/OR V3.

\section{DED diagnosis}

168 Our secondary outcome was the presence of DED. According to the TFOS DEWS II

169 Diagnostic Methodology report, DED was diagnosed in presence of a "screening" $170 \mathrm{OSDI} \geq 13$ plus at least 1 of the following "homeostasis markers": tear film osmolarity $171 \geq 308 \mathrm{mOsm} / \mathrm{L}$ or interocular difference $>8 \mathrm{mOsm} / \mathrm{L}, \mathrm{T}-\mathrm{BUT}<10$ seconds, and positive 172 corneal, conjunctival or lid margin staining. ${ }^{19}$

173 OSFI development

174 We borrowed the concept of frailty and we built the OSFI following and adapting the

175 "standard procedure for creating a frailty index" previously described and validated by 176 Searle SD et al. ${ }^{12}$

177 Briefly, OSFI is based on a count of "deficits in ocular surface health and/or factors 178 potentially able to affect it". Each investigator independently proposed a list of 30 179 "candidate items". Agreement on the preliminary list of 19 items was then obtained through 180 open discussion, paying attention to include variables which were associated with ocular 181 surface health status, whose prevalence generally increase with age, and which 
182

183

184

don't saturate too early (for instance, presbyopia is nearly universal by age 55 , saturating too early to be included in this type of frailty index $)^{12}$ Moreover, when considering the candidate deficits as a group, we selected the preliminary list trying to cover a range of systems and mechanisms having an impact on the ocular surface health. Finally we prioritized variables easily, quickly and cheaply assessable.

All binary variables were recorded using the convention that " 0 " indicates the absence of the deficit, and "1" the presence of it. Continuous and ordinal variables were graded into a score between "0" and "1", after testing different strategies for their categorization. The index is then expressed as: positive items/total number of assessed items.

The preliminary OSFI composition is reported in Table 2 (available at www.aaojournal.org).

In order to optimize the OSFI composition, we performed Spearman correlation and univariate logistic analysis to assess associations between each preliminary OSFI item and the development of post-surgical DED symptoms. We excluded the items showing a negative correlation coefficient and then we adopted a stepwise approach, progressively excluding the items with the weakest association for the outcome, defined as the highest $\mathrm{P}$ value in the regression model. At each step, OSFI score was re-calculated and its predictive value for the main outcome was re-tested on a bootstrap of 200 samples. This process was stopped when, moving from 10 to 9 items, the OSFI predictive value decreased, showing an higher $\mathrm{P}$ value of the regression analysis (Table 3).

We tested different strategies for continuous and ordinal items categorization, selecting the ones providing the best OSFI predictive value.

The final OSFI composition, including 10 items, is reported in Table 4.

We assessed OSFI Inter-observer reproducibility on an external group of 20 patients undergoing cataract surgery. Two investigators (EV, FB) independently examined the patients and quantified the OSFI score in 2 consecutive days. 


\section{Statistical analysis}

209 In descriptive statistics, normally distributed variables were presented as mean \pm standard 210 deviation (SD), non-normally distributed variables were presented as median (interquartile 211 range), and categorical variables as number (percentage).

212 Comparisons between groups were made using Mann-Whitney $U$ test for continuous 213 variables, dependent on distribution, and $x^{2}$ test for categorical variables.

214 Correlations between continuous variables were tested by Spearman's correlation 215 coefficient.

216 Receiver Operating Characteristic (ROC) curve analysis was used to identify the optimal 217 OSFI cut-off point for development of post-surgical DED symptoms.

218 Multivariable logistic regression analysis was performed in a standard stepwise approach, 219 with inclusion of significant variables $(P<0.05)$ after univariable regression.

220 Bootstrapping was performed on 200 samples, with simple sampling strategy and $95 \% \mathrm{Cl}$.

221 Inter-observer reproducibility was assessed by Interclass Correlation Coefficient (ICC). The 222 minimum criterion for tests of significance was $\mathrm{P}<0.05$.

223 Statistical analysis was conducted using a commercial software (SPSS for Windows, v. 20; 224 SPSS Sciences, Chicago, IL).

225 Results

226 The mean age of the 284 included patients was $74.53 \pm 8.16$ years; $105(37 \%)$ were males. 227 At baseline, given the exclusion criteria, none of the included patients showed DED 228 symptoms (OSDI $\geq 13)$. However, 206 patients (72.5\%) had at least one DED sign without 229 symptoms. Specifically, positive values of tear osmolarity, T-BUT and ocular surface 230 fluorescein staining ${ }^{19}$ were found in 64 (22.5\%), 185 (65.1\%), and 53 (18.7\%) patients, 231 respectively.

232 The overall cumulative percentage of patients showing ocular surface symptoms at V2 233 AND/OR V3 was 17\% (48 of 284), Table 5. Of these patients, 36 (75\%) fulfilled the DED 
234 diagnostic criteria in at least 1 follow-up visit.

235 Univariate logistic regression showed that age and gender had no association with DED symptoms onset after cataract surgery $(\mathrm{OR}=0.98(0.95-1.02), \mathrm{P}=0.38$ and $\mathrm{OR}=1.26(0.65$ 2.41), $P=0.49$, respectively)..

Moreover, no baseline DED sign showed to be a significant predictor for post-operative onset of symptoms $(\mathrm{P}=0.25, \mathrm{P}=0.10$, and $\mathrm{P}=0.44$ for osmolarity, $\mathrm{T}-\mathrm{BUT}$, and staining, 240 respectively).

241 Our patients' OSFI score ranged from 0 to 0.666 , with a median value of $0.200(0.133-$ $2420.266)$

243 The prevalence of each OSFI item is shown in Figure 1 (available at www.aaojournal.org) 244 and in Table 3; the 5 most common components were reduced T-BUT (185 [65\%]), 245 computer usage (83 [29\%]), psychiatric conditions (80 [28\%]), LIPCOF=3 (54 [19\%]), and 246 MGs expressibility=3 (41 [14\%]).

247 The twenty patients assessed for inter-observer reproducibility showed almost perfect 248 agreement $(I C C=0.93)$ in OSFI score quantification between EV $(0.216$ [0.162-0.370]) and 249 FB $(0.225[0.162-0.362])$.

250 OSFI score of patients who showed DED symptoms at V2 AND/OR V3 (0.300 [0.233$2510.399])$ was significantly higher of the score $(0.166[0.116-0.249])$ of patients without post252 surgical symptoms $(\mathrm{P}<0.001$, Mann-Whitney $U$ test).

253 In order to support the OSFI construct validity, we compared the rate of post-operative 254 symptoms of patients with the lowest OSFI values (10th percentile) vs the rate of 255 symptoms of patients with the highest OSFI values (90th percentile): 0 vs 18/28 (64\%); $256 \mathrm{P}<0.001, \mathrm{X}^{2}$ test. Moreover, we compared OSFI values of patients with the lowest $\max$ 257 post-operative OSDI values (10th percentile) vs OSFI values of patients with the highest 258 max post-operative OSDI values (90th percentile): $0.183(0.108-0.249)$ vs $0.333(0.233-$ 259 0.433); $P<0.001$, Mann-Whitney $U$ test. 
260 In a logistic regression model, none of the OSFI components showed to be a significant 261 predictor of DED symptoms' onset (Table 3).

262 On ROC curve analysis, the area under the curve was 0.821 . OSFI value of 0.241 , with 263 sensitivity of $74 \%$ and specificity of $77 \%$, showed the highest Youden index. However, 264 setting the specificity to $90 \%$, we found a cut-off of 0.3 (sensitivity $=53 \%$ ) (Figure 2 ).

265 In our population, we found 230 (81\%) patients with OSFI<0.3 and $54(19 \%)$ patients with 266 frail ocular surface (OSFI $\geq 0.3)$; figure 3.

267 The rate of post-operative DED symptoms was significantly higher in patients with frail 268 ocular surface $(27$ of $54 ; 50 \%)$ than in patients with robust ocular surface (22 of $230 ; 9 \%)$; $269 \quad P<0.001, X^{2}$ test.

270 Logistic regression analysis showed that OSFI $\geq 0.3$ was a good predictor of ocular surface symptoms onset (odds ratio $(\mathrm{OR})=9.45 ; 95 \% \mathrm{Cl}(4.74-18.82) . \mathrm{P}<0.001)$. No significant changes were found after adjusting the analysis for age and gender (OR=9.35 (4.6818.68), $\mathrm{P}<0.001)$.

Bootstrapping 200 samples, $\mathrm{Cl}$ of this logistic analysis remained above 1.0 (1.58-2.99);

$275 \quad P<0.01$.

276 OSFI $\geq 0.3$ was a significant predictor also for the development of post-surgical DED 277 (defined as symptoms + at least 1 sign): $\mathrm{OR}=3.54 ; 95 \% \mathrm{Cl}(1.73-7.21) ; \mathrm{P}<0.001$.

\section{Discussion}

279 Even if the advanced age can carry increased risk of post-surgical adverse events, 280 the chronological age is not suitable to be used as a tool for pre-operative risk 281 assessment and stratification. ${ }^{22,23,24}$ The concept of frailty arises from the need to identify 282 those individual with decreased functional capacity, and therefore to identify patients with 283 an increased risk of post-surgical negative events. ${ }^{11,23,24} \mathrm{~A}$ large growing body of literature 284 shows the importance 285 of measuring frailty before performing several different types of surgeries and the Frailty 
286 Indexes, although not yet optimized and adequately standardized, are reported to be one 287 of the most prominent tools for patients' risk stratification. ${ }^{23,24}$

288 Age-related cataract surgery is a very common geriatric surgery with no (or maybe with 289 beneficial) impact on mortality and systemic morbidity, ${ }^{25}$ able to clearly improve visual 290 function and quality of life,$^{26}$ but associated with a relevant risk of inducing or worsening 291 ocular surface symptoms. ${ }^{4}$ Several studies focused on the multifactorial 292 pathophysiological mechanisms underlying cataract surgery-induced DED, including the 293 use of topical anesthetics and exposure desiccation, possible light toxicity from the 294 operating microscope, nerve transection, elevation of inflammatory factors, goblet cell loss, 295 and meibomian gland dysfunction, and on the most effective therapeutic approaches for 296 this condition. ${ }^{4}$ However, at present, there are no validated tools to be used for stratifying 297 the risk of a clinically relevant negative impact of cataract surgery on the ocular surface 298 health. Previous studies, with heterogeneous designs, populations, and methodologies, 299 explored the predictive value of several peri-operative parameters (e.g. age, diabetes, 300 socio-economic status, site of incision, microscope light exposure time, ...). ${ }^{27-29}$ These 301 reports showed conflicting results and failed to provide consistent evidence ${ }^{3}$ supporting the use of any of these parameters for risk assessment. Our results confirmed this issue, 303 showing that no baseline personal or clinical data would be a significant predictor of the 304 development of post-surgical symptoms.

305 The TFOS DEWS II latrogenic report generically stated that "even in the absence of 306 DED, ocular surface disease should be managed before cataract surgery". ${ }^{4}$ This 307 recommendation highlights the peculiar challenge represented by the relevant percentage 308 (17\% in our study population) of asymptomatic patients developing ocular surface 309 symptoms after surgery.

310 We designed and developed the OSFI starting from the concept of frailty and its different 311 applications for pre-operative risk assessment in general and geriatric surgery.. This novel 
tool, simultaneously evaluating several different potential mechanisms and markers of "deficits in ocular surface health", might allow performing effective pre-operative risk stratification. The identification of non-DED patients more susceptible to develop surgeryrelated ocular surface symptoms and DED might be useful to improve patient-doctor communication, to adjust patients' expectations, reducing the subsequent dissatisfaction and to plan a more personalized and successful management of the patients' ocular surface.

We included in the preliminary OSFI 19 items, related to medical history and clinical findings, that we considered being potentially important "deficits in ocular surface health or factors potentially able to affect it". Most of these items have been classified by the TFOS DEWS II Epidemiology Report as "consistent" or "probable" risk factors for DED. ${ }^{3}$ Moreover, we paid attention to select items suitable to be easily, quickly and cheaply assessed in the context of a general ophthalmic clinical setting/ cataract service. For this reason, we avoided to include in the OSFI data requiring high-tech, time-consuming, expensive exams or procedures broadly used just in cornea/ocular surface reference centers (e.g. OCT meniscometry, tear film osmolarity, infrared meibography, ...). In order to improve both the OSFI predictive value and clinical utility, we excluded from the preliminary index the items showing negative and weak positive correlations with the outcome. This process led to the definition of the final OSFI, including 10 items. Nevertheless, OSFI quantification would require adding some extra minutes to the preoperative examination of patients and this might limit its spread and use in daily clinical practice. However, given the relevance of the potential post-operative issue, ${ }^{4,8}$ this seems to be a reasonable effort to be done in order to perform an effective risk assessment. Our selection of OSFI components is somewhat arbitrary and might be refined through future studies. However, this issue is inherent in all the processes aimed to build new tools for frailty assessment and, interestingly, previous studies showed that, if the selection 
338 criteria are properly applied, the results are insensitive to the precise composition of the 339 index. ${ }^{12,30}$

340 The OSFI cut-off of 0.3 allowed us to identify a small group (19\% of the asymptomatic 341 subjects) of patients with a frail ocular surface morpho-functional unit, at high risk to 342 develop post-operative ocular surface symptoms. These patients might be managed with a 343 personalized approach, both before and after surgery, including not only tailored therapies 344 but also a peculiar communication effort.

345 In order to validate the OSFI score, we considered its inter-observer reproducibility, and 346 content and construct validity.

347 Reproducibility was tested in the most challenging conditions, with 2 independent 348 investigators quantifying the Index in 2 different days, and it showed an almost perfect 349 inter-observer agreement.

350 Content validity of the preliminary OSFI was partly assured by its development procedure, 351 based on agreement among experts (the investigators) working on updated evidences on 352 the topic, recently selected by the TFOS DEWS II panel. ${ }^{3}$ Content validity of the final OSFI 353 was assessed arranging in a matrix 4 key etiologic domains of DED ${ }^{31}$ and the OSFI items 354 (Table 6, available at www.aaojournal.org). The final OSFI items seem to be well355 distributed and related to tear film instability, ocular surface inflammation, neuro-sensory 356 abnormalities, and ocular surface epithelial damage. Interestingly, the stepwise process 357 excluded ocular surface fluorescein staining and Schirmer test from the final OSFI.

358 Patients with severe epitheliopathy and/or severely reduced tears secretion are generally 359 symptomatic and they were excluded at the screening visit. About mild epitheliopathy 360 and/or hypersecretion, these results might further confirm the well-known lack of 361 correlation between DED signs and symptoms. ${ }^{32}$ Moreover, a proportion of normal 362 corneas, especially after the age of 50 , show punctate fluorescein uptake. ${ }^{33}$

363 This is the first paper theorizing and proposing the concept of ocular surface frailty, and 
developing a tool for its assessment. In the absence of other reference tools for ocular surface frailty quantification and in order to support the OSFI construct validity, we demonstrated that the rate of post-operative symptoms of the patients with the lowest OSFI values (10th percentile) was 0 and the rate of symptoms of the patients with the highest OSFI values (90th percentile) was $64 \%$. We also demonstrated that the patients with the highest max post-operative OSDI values (90th percentile) had significantly higher OSFI values than the patients with the lowest max post-operative OSDI values (10th percentile).

We did not assess OSFI internal consistency. The presence of strong correlations among the items is important in scales including items tapping a single domain or attribute. In indexes like OSFI, the items are not manifestations of an underlying construct (effect indicators) but the items themselves define the construct (causal indicators). In this type of tools, the items may or may not covariate, irrespective of their relationship with the construct. $^{34}$

Finally, we supported the internal validation of OSFI performing the stepwise process for the final index definition and the logistic regression analysis of the index cut-off predictivity on a bootstrap of 200 samples.

External validation, however, remains the gold standard to assess the true validity of OSFI when applied to other patient samples, and this will be our next step. External validation will have to be performed on a larger, multi-centric, more heterogeneous population, including patients undergoing cataract surgery with multifocal IOL implantation. This latter point is of particular importance since these patients have especially high pre-operative expectations and ocular surface symptoms may significantly affect patients' perception of the surgery's outcome.

This study has other limitations, including the short follow-up. However, this research was focused on cataract surgery-related DED symptoms onset, reported mainly in the first 
weeks after surgery, ${ }^{6,7}$ and not on their course.

391 In conclusion, we built a novel tool in order to assess the frailty of the ocular surface of 392 patients undergoing cataract surgery. The OSFI, which showed to be the only significant 393 predictor of ocular surface symptoms onset in our patients, will have to be validated in 394 different and larger populations. This tool might be refined and maybe adapted to the 395 reality of the different Countries, but we think that this type of novel application of the 396 concept of frailty could contribute to improve our capabilities to have an effective and personalized approach to the ocular surface of patients undergoing cataract surgery.

\section{References}

407 1. Lam D, Rao SK, Ratra V, et al. Cataract. Nat Rev Dis Primers. 2015;1:15014.

$408 \quad 2 . \quad$ Clayton JA. Dry Eye. N Engl J Med. 2018;378:2212-2223.

409 3. Stapleton F, Alves M, Bunya VY, et al. TFOS DEWS II Epidemiology Report. Ocul 410 Surf. 2017;15:334-365.

411 4. Gomes JAP, Azar DT, Baudouin C, et al. TFOS DEWS II iatrogenic report. Ocul Surf. 2017;15:511-538.

413 5. Szakáts I, Sebestyén M, Tóth É PG. Dry Eye Symptoms, Patient-Reported Visual Functioning, and Health Anxiety Influencing Patient Satisfaction After Cataract Surgery. Curr Eye Res. 42:832-8365. 
416 6. Cetinkaya S, Mestan E, Acir NO, Cetinkaya YF, Dadaci Z YH. The course of dry eye after phacoemulsification surgery. BMC Ophthalmol. 2015;5:68.

7. Kasetsuwan N, Satitpitakul V, Changul T, Jariyakosol S. Incidence and pattern of dry eye after cataract surgery. PLoS One. 2013;8:e78657.

9. Chen X, Mao G, Leng SX. Frailty syndrome: An overview. Clin Interv Aging. 2014;9:433-441.

12. Searle SD, Mitnitski A, Gahbauer EA, Gill TM, Rockwood K. A standard procedure for creating a frailty index. BMC Geriatr. 2008;8.

13. Darvall JN, Gregorevic KJ, Story DA, Hubbard RE, Lim WK. Frailty indexes in perioperative and critical care: A systematic review. Arch Gerontol Geriatr. 2018;79:88-96.

14. Abt NB, Richmon JD, Koch WM, Eisele DW, Agrawal N. Assessment of the predictive value of the modified frailty index for Clavien-Dindo grade IV critical care complications in major head and neck cancer operations. JAMA Otolaryngol - Head Neck Surg. 2016;142:658-664.

15. Seib CD, Rochefort $\mathrm{H}$, Chomsky-Higgins $\mathrm{K}$, et al. Association of patient frailty with increased morbidity after common ambulatory general surgery operations. JAMA Surg. 2018;153:160-168. 
16. Shi S, Afilalo J, Lipsitz LA, et al. Frailty Phenotype and Deficit Accumulation Frailty Index in Predicting Recovery After Transcatheter and Surgical Aortic Valve Replacement. J Gerontol A Biol Sci Med Sci. 2018 Aug 25.

doi:10.1093/gerona/gly196. [Epub ahead of print]

17. Esses GJ, Liu X, Lin HM, Khelemsky Y, Deiner S. Preoperative frailty and its association with postsurgical pain in an older patient cohort. Reg Anesth Pain Med. 2019 May 6. pii: rapm-2018-100247.

18. Schiffman RM, Christianson MD, Jacobsen G, Hirsch JD RB. Reliability and validity of the ocular surface disease index. Arch Ophthalmol. 2000;118:615-21.

19. Wolffsohn JS, Arita R, Chalmers R, et al. TFOS DEWS II Diagnostic Methodology report. Ocul Surf. 2017;15:539-574.

20. Geerling G, Tauber J, Baudouin C, et al. The international workshop on meibomian gland dysfunction: report of the subcommittee on management and treatment of meibomian gland dysfunction. Invest Ophthalmol Vis Sci 2011;52:2050e64.

21. Pult H, Purslow C, Murphy PJ. The relationship between clinical signs and dry eye symptoms. Eye (Lond) 2011;25:502e10.

22. Miller KL, Walt JG, Mink DR, et al. Minimal clinically important difference for the ocular surface disease index. Arch Ophthalmol. 2010;128:94-101.

23. Lin HS, Watts JN, Peel NM, Hubbard RE. Frailty and post-operative outcomes in older surgical patients: a systematic review. BMC Geriatr. 2016;16:157.

24. Buigues C, Juarros-Folgado P, Fernández-Garrido J, Navarro-Martínez R, Cauli O. Frailty syndrome and pre-operative risk evaluation: A systematic review. Arch Gerontol Geriatr. 2015;61:309-21.

25. Song E, Sun $\mathrm{H}, \mathrm{Xu} Y, \mathrm{Ma} Y$, Zhu H, Pan CW. Age-related cataract, cataract surgery and subsequent mortality: a systematic review and meta-analysis. PLoS One. 2014;9:e112054. 
26. Shekhawat NS, Stock MV, Baze EF, et al. Impact of First Eye versus Second Eye Cataract Surgery on Visual Function and Quality of Life. Ophthalmology. 2017;124:1496-1503.

27. Jiang D, Xiao X, Fu T, Mashaghi A, Liu Q, Hong J. Transient Tear Film Dysfunction after Cataract Surgery in Diabetic Patients. PLoS One. 2016;11:e0146752.

28. Park Y, Hwang H Bin, Kim HS. Observation of influence of cataract surgery on the ocular surface. PLoS One. 2016;11:e0152460.

29. Kohli P, Arya SK, Raj A, Handa U. Changes in ocular surface status after phacoemulsification in patients with senile cataract. Int Ophthalmol. 2018 Jun 20. doi: 10.1007/s10792-018-0953-8. [Epub ahead of print]

30. Rockwood K, Andrew M, Mitnitski A. A Comparison of two approaches to measuring frailty in elderly people. J Gerontol A Biol Sci Med Sci 2007, 62A:738-743.

31. Craig JP, Nichols KK, Akpek EK, et al. TFOS DEWS II Definition and Classification Report. Ocul Surf. 2017;15:276-283.

32. Sullivan BD, Crews LA, Messmer EM, et al. Correlations between commonly used objective signs and symptoms for the diagnosis of dry eye disease: clinical implications. Acta Ophthalmol. 2014;92:161-6.

33. Bron AJ, Argüeso P, Irkec M, Bright FV. Clinical staining of the ocular surface: mechanisms and interpretations. Prog Retin Eye Res. 2015;44:36-61.

34. Streiner DL. Being inconsistent about consistency: when coefficient alpha does and doesn't matter. J Pers Assess. 2003;80:217-22. 
$499 \quad$ Figure legends

500 Figure 1. Population prevalence of OSFI components.

501 The prevalence of OSFI components ranged from $65 \%$ for BUT<10seconds to $0.7 \%$ for

502 connective tissue diseases. T-BUT: fluorescein tear film break-up time; LIPCOF: lid 503 parallel conjunctival folds; MGs: Meibomian glands; OSDI: Ocular Surface Disease Index.

504 Figure 2. Receiver Operating Curve Analysis for post-operative DED symptoms 505 onset.

506 The Area Under the Curve (AUC) was 0.821 . OSFI score of 0.241 showed the highest, 507 with sensitivity of $74 \%$ and specificity of $77 \%$, showed the highest Youden index. OSFI cut508 off of 0.3 had sensitivity of $53 \%$ and specificity of $90 \%$.

509 Figure 3. Distribution of Ocular Surface Frailty Index scores.

510 Higher values indicate a higher degree of frailty. 54 patients (19\%) had a frail ocular 511 surface, with OSFI $\geq 0.3$. 


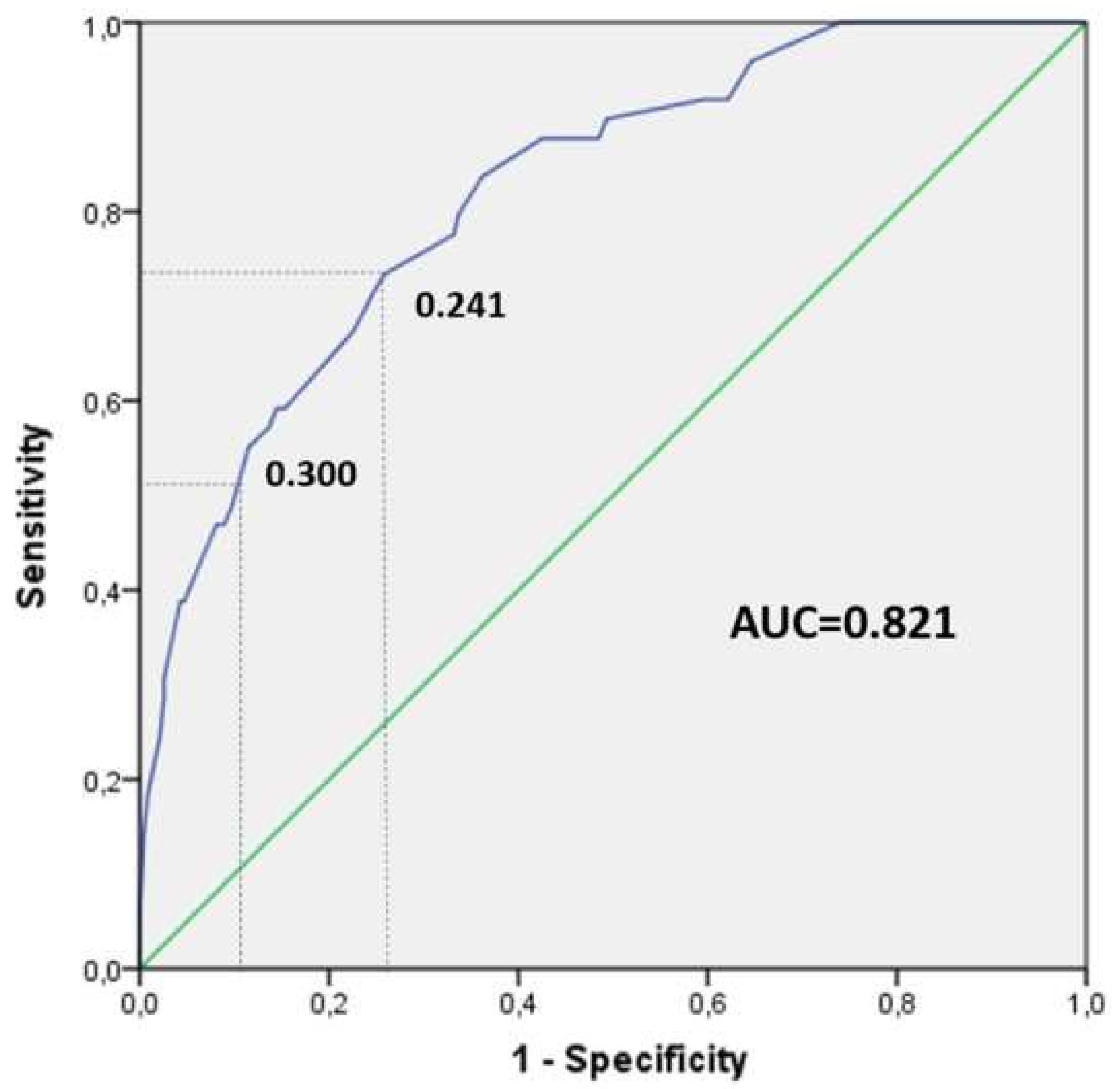

\section{$A U C=0.821$}


Click here to access/download;Figure;OSFI distribution.tif $\stackrel{\star}{ }$

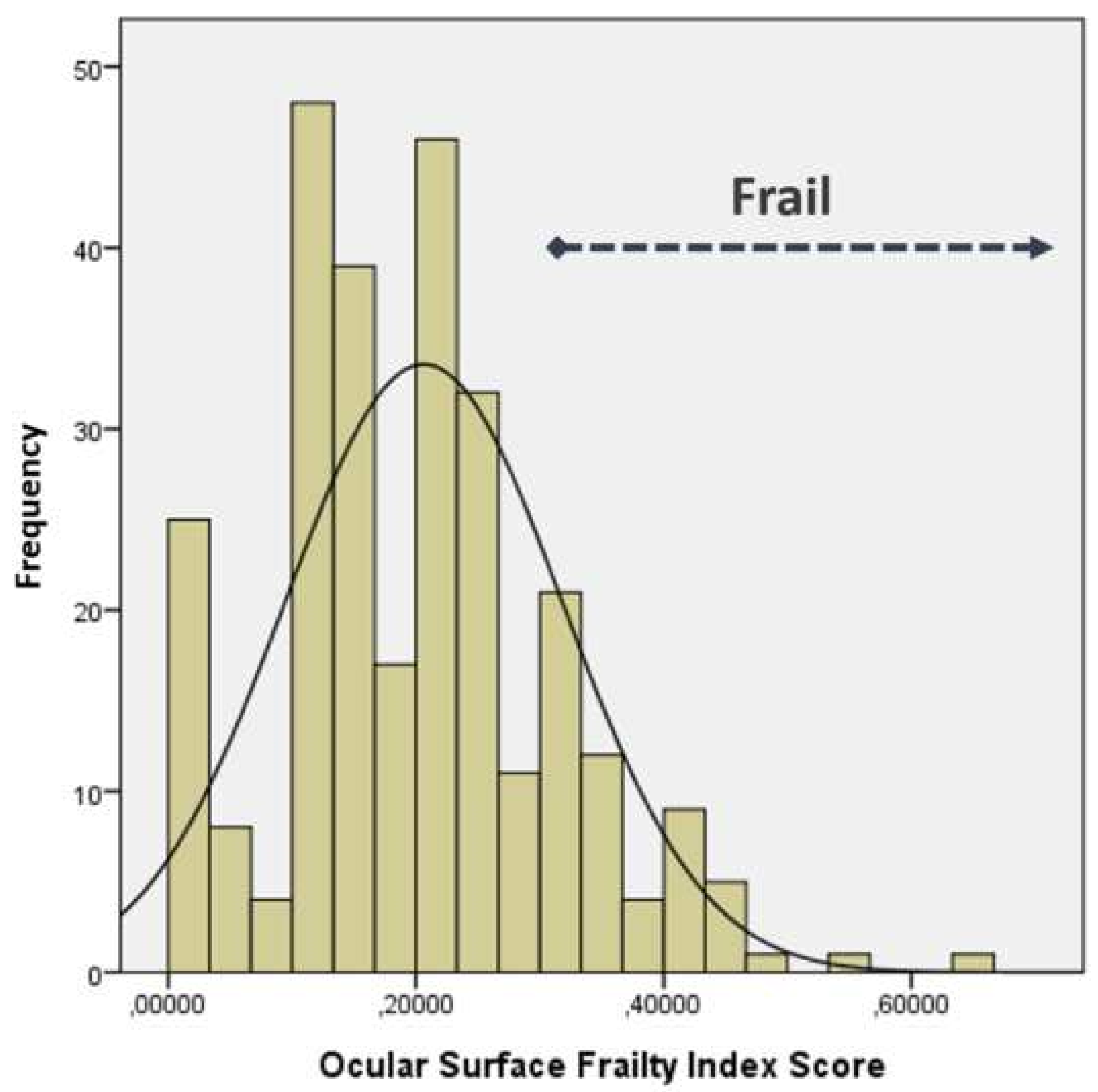


Table 5. Ocular surface symptoms at each follow-up visit: prevalence and first onset.

\begin{tabular}{|l|c|c|c|c|}
\hline & V1 (1 week) & V2 (1 month) & V3 (3 months) & V2 AND/OR V3 \\
\hline $\begin{array}{l}\text { Prevalence of ocular } \\
\text { surface symptoms: } \mathbf{n}(\%)\end{array}$ & $3(1 \%)$ & $28(10 \%)$ & $36(13 \%)$ & $48(17 \%)$ \\
\hline $\begin{array}{l}\text { First onset of ocular } \\
\text { surface symptoms: } \mathbf{n}(\%)\end{array}$ & $3(1 \%)$ & $26(10 \%)$ & $20(7 \%)$ & - \\
\hline
\end{tabular}


Table 3. Logistic regression model for each preliminary OSFI item and stepwise OSFI optimization

\begin{tabular}{|c|c|c|c|c|c|c|c|c|}
\hline \multicolumn{2}{|l|}{ Item } & \multirow{2}{*}{$\begin{array}{l}\text { Spearman } \\
r\end{array}$} & \multicolumn{3}{|c|}{$\begin{array}{l}\text { Single items } \\
\text { logistic regression } \\
\text { analysis }\end{array}$} & \multicolumn{3}{|c|}{$\begin{array}{l}\text { OSFI } \\
\text { logistic regression analysis } \\
\text { bootstrapping } 200 \text { samples }\end{array}$} \\
\hline & $\begin{array}{l}\text { Prevalence } \\
\mathrm{N}(\%)\end{array}$ & & OR & $\begin{array}{l}95 \% \\
\mathrm{Cl}\end{array}$ & $P$ & $\begin{array}{l}\mathrm{N} \text { items } \\
\text { included } \\
\text { in OSFI }\end{array}$ & $95 \% \mathrm{Cl}$ & $P$ \\
\hline Pterygium & 0 & - & - & - & - & 19 & $\begin{array}{l}0.67- \\
9.01\end{array}$ & 0.030 \\
\hline Rosacea & $3(1 \%)$ & -0.047 & ND & ND & ND & 18 & $\begin{array}{l}0.05- \\
7.96\end{array}$ & 0.035 \\
\hline Contact lenses wear & $6(2 \%)$ & -0.001 & ND & ND & ND & 17 & $\begin{array}{l}0.40- \\
7.41\end{array}$ & 0.025 \\
\hline Fluorescein staining & $53(19 \%)$ & 0.008 & 1.63 & $\begin{array}{l}0.09- \\
11.50\end{array}$ & 0.53 & 16 & $\begin{array}{l}0.87- \\
7.64\end{array}$ & 0.025 \\
\hline Schirmer test & $52(18 \%)$ & 0.008 & 1.21 & $\begin{array}{l}0.44- \\
3.29\end{array}$ & 0.71 & 15 & $\begin{array}{l}1.13- \\
7.00\end{array}$ & 0.020 \\
\hline Diabetes & $40(14 \%)$ & 0.016 & 1.12 & $\begin{array}{l}0.51- \\
2.75\end{array}$ & 0.69 & 14 & $\begin{array}{l}1.37- \\
7.11 \\
\end{array}$ & 0.005 \\
\hline Topical drugs & $29(10 \%)$ & 0.026 & 1.08 & $\begin{array}{l}0.32- \\
3.18\end{array}$ & 0.62 & 13 & $\begin{array}{l}1.06- \\
7.56\end{array}$ & 0.005 \\
\hline Conjunctivochalasis & $238(84 \%)$ & 0.016 & 1.12 & $\begin{array}{l}0.54- \\
2.81\end{array}$ & 0.61 & 12 & $\begin{array}{l}1.37- \\
7.71\end{array}$ & 0.005 \\
\hline $\begin{array}{l}\text { Hormone } \\
\text { replacement } \\
\text { therapy }\end{array}$ & $7(2 \%)$ & 0.074 & 3.36 & $\begin{array}{l}0.33- \\
8.73\end{array}$ & 0.60 & 11 & $\begin{array}{l}2.18- \\
8.29\end{array}$ & 0.005 \\
\hline LIPCOF & $54(19 \%)$ & 0.030 & 1.52 & $\begin{array}{l}0.39- \\
5.95\end{array}$ & 0.55 & 10 & $\begin{array}{l}2.04- \\
8.07 \\
\end{array}$ & 0.005 \\
\hline Thyroid malfunction & $37(13 \%)$ & 0.077 & 1.65 & $\begin{array}{l}0.64- \\
4.27\end{array}$ & 0.30 & 9 & $\begin{array}{l}1.30- \\
6.99\end{array}$ & 0.015 \\
\hline TBUT & $185(65 \%)$ & 0.096 & 1.95 & $\begin{array}{l}0.64- \\
5.78\end{array}$ & 0.26 & 8 & $\begin{array}{l}1.08- \\
7.52 \\
\end{array}$ & 0.015 \\
\hline Ocular allergy & $19(7 \%)$ & 0.105 & 2.22 & $\begin{array}{l}0.72- \\
6.86\end{array}$ & 0.16 & 7 & $\begin{array}{l}0.96- \\
6.63\end{array}$ & 0.015 \\
\hline $\begin{array}{l}\text { Psychiatric } \\
\text { conditions }\end{array}$ & $80(28 \%)$ & 0.098 & 2.25 & $\begin{array}{l}0.76- \\
6.61\end{array}$ & 0.14 & 6 & $\begin{array}{l}0.98- \\
6.25 \\
\end{array}$ & 0.020 \\
\hline $\begin{array}{l}\text { Systemic } \\
\text { medications }\end{array}$ & $124(44 \%)$ & 0.179 & 1.70 & $\begin{array}{l}0.83- \\
3.48\end{array}$ & 0.15 & 5 & $\begin{array}{l}-0.17- \\
4.83 \\
\end{array}$ & 0.055 \\
\hline $\begin{array}{l}\text { Meibomian glands } \\
\text { expressibility }\end{array}$ & $41(14 \%)$ & 0.110 & 1.88 & $\begin{array}{l}0.78- \\
5.82\end{array}$ & 0.15 & 4 & ND & ND \\
\hline Computer use & $83(29 \%)$ & 0.123 & 1.90 & $\begin{array}{l}0.82- \\
4.34\end{array}$ & 0.13 & 3 & ND & ND \\
\hline $\begin{array}{l}\text { Connective tissue } \\
\text { diseases }\end{array}$ & $2(0.7 \%)$ & 0.184 & ND & ND & ND & 2 & ND & ND \\
\hline $\begin{array}{l}\text { History of refractive } \\
\text { surgery }\end{array}$ & $2(0.7 \%)$ & 0.184 & ND & ND & ND & 1 & ND & ND \\
\hline
\end{tabular}


Table 4. Final Ocular Surface Frailty Index composition

\begin{tabular}{|c|c|c|}
\hline 1. Connective tissue diseases & $\begin{array}{l}\text { No } \\
\text { Yes }\end{array}$ & $\begin{array}{l}0 \text { points } \\
1 \text { point }\end{array}$ \\
\hline 2. Thyroid malfunction & $\begin{array}{l}\text { No } \\
\text { Yes }\end{array}$ & $\begin{array}{l}0 \text { points } \\
1 \text { point }\end{array}$ \\
\hline 3. Psychiatric conditions ${ }^{*}$ & $\begin{array}{l}\text { No } \\
\text { Yes }\end{array}$ & $\begin{array}{l}0 \text { points } \\
1 \text { point }\end{array}$ \\
\hline 4. Computer use ${ }^{\star \star}$ & $\begin{array}{l}\text { No } \\
\text { Yes }\end{array}$ & $\begin{array}{l}0 \text { points } \\
1 \text { point }\end{array}$ \\
\hline 5. Ocular allergy & $\begin{array}{l}\text { No } \\
\text { Yes }\end{array}$ & $\begin{array}{l}0 \text { points } \\
1 \text { point }\end{array}$ \\
\hline 6. History of refractive surgery & $\begin{array}{l}\text { No } \\
\text { Yes }\end{array}$ & $\begin{array}{l}0 \text { points } \\
1 \text { point }\end{array}$ \\
\hline 7. Topical drugs ${ }^{\star \star \star}$ & $\begin{array}{l}\text { No } \\
\text { Yes }\end{array}$ & $\begin{array}{l}0 \text { points } \\
1 \text { point }\end{array}$ \\
\hline $\begin{array}{l}\text { 8. TBUT } \\
\text { with fluorescein }\end{array}$ & $\begin{array}{l}\geq 10 \mathrm{~s} \\
5-9 \mathrm{~s} \\
0-4 \mathrm{~s}\end{array}$ & $\begin{array}{l}0 \text { points } \\
0,50 \text { points } \\
1 \text { point }\end{array}$ \\
\hline $\begin{array}{l}\text { 9. Meibomian glands expressibility } \\
\text { (digital expression) }\end{array}$ & $\begin{array}{l}\text { Grade 0: clear meibum easily expressed } \\
\text { Grade 1: cloudy meibum expressed with } \\
\text { mild pressure } \\
\text { Grade 2: cloudy meibum expressed with } \\
\text { moderate pressure } \\
\text { Grade 3: meibum not expressed with } \\
\text { more than moderate pressure }\end{array}$ & $\begin{array}{l}0 \text { points } \\
0,33 \text { points } \\
0,66 \text { points } \\
1 \text { point }\end{array}$ \\
\hline 10.LIPCOF & $\begin{array}{l}\text { Grade } 0 \\
\text { Grade } 1 \\
\text { Grade } 2 \\
\text { Grade } 3 \\
\end{array}$ & $\begin{array}{l}0 \text { points } \\
0,33 \text { points } \\
0,66 \text { points } \\
1 \text { point }\end{array}$ \\
\hline
\end{tabular}

*: Including affective, somatoform disorders, anxiety and depression

$* *$ : Exposure $>4$ hours/day

***: Current use of at least one of the following topical drugs: antiglaucomatous, antiallergic, antiviral, decongestants, miotics, mydriatics, non-steroidal anti-inflammatory OR at least 3 drops/day BAK preserved 


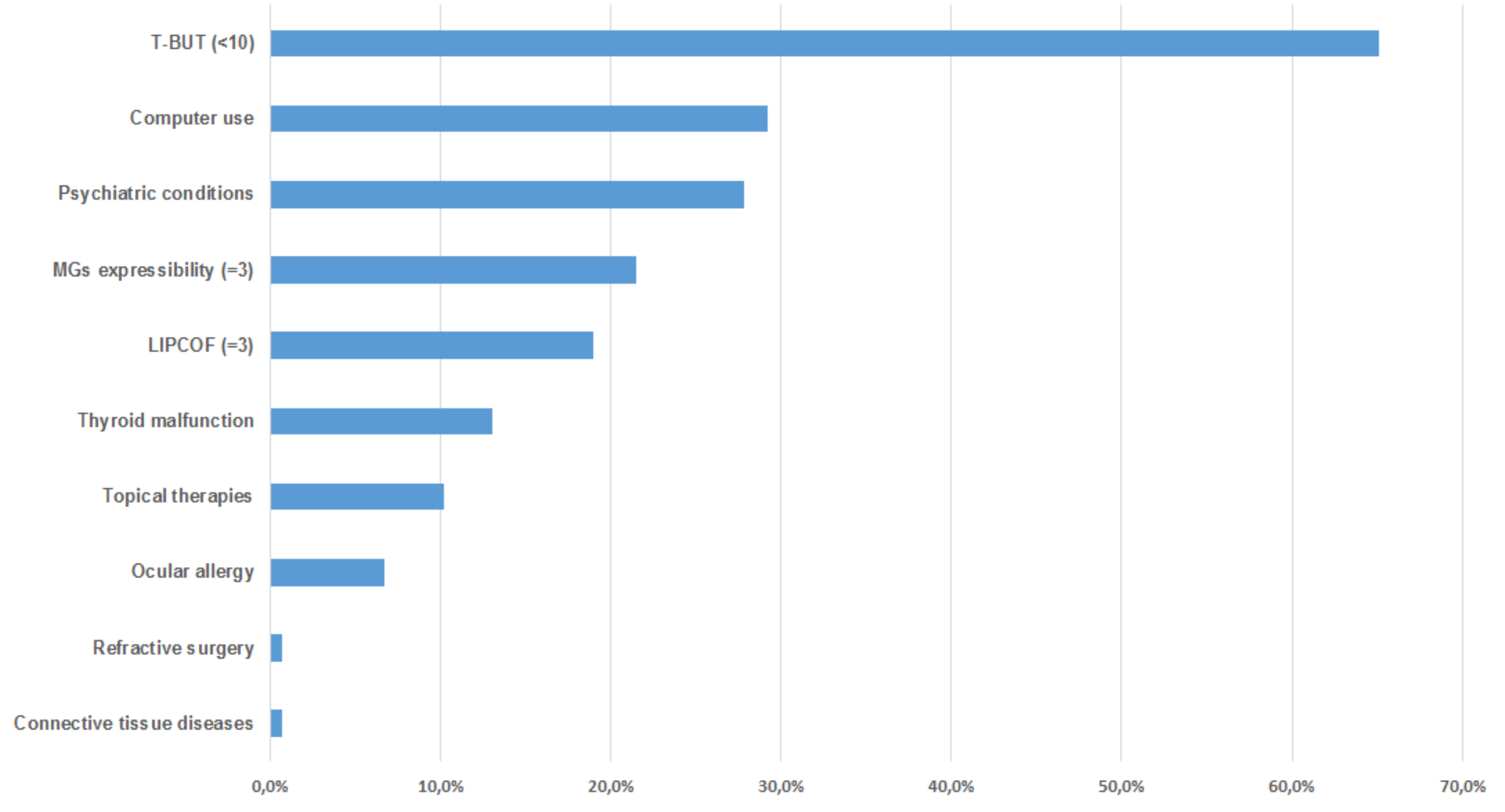

Patients, \% 
Table 1. Procedures scheduled at each visit

\begin{tabular}{|c|c|c|c|c|}
\hline Procedures & Vo & V1 & V2 & V3 \\
\hline $\begin{array}{l}\text { Anamnestic } \\
\text { questionnaire }\end{array}$ & $X$ & & & \\
\hline OSDI & $X$ & $X$ & $X$ & $\mathrm{X}$ \\
\hline $\begin{array}{l}\text { Tear film } \\
\text { osmolarity }\end{array}$ & $X$ & $\mathrm{X}^{*}$ & $X^{*}$ & $\mathrm{X}^{*}$ \\
\hline T-BUT & $X$ & $X^{*}$ & $\mathrm{X}^{*}$ & $X^{*}$ \\
\hline $\begin{array}{l}\text { Fluorescein } \\
\text { staining }\end{array}$ & $X$ & $\mathrm{X}^{*}$ & $X^{*}$ & $\mathrm{X}^{*}$ \\
\hline $\begin{array}{l}\text { Meibomian glands } \\
\text { expression }\end{array}$ & $\mathrm{X}$ & & & \\
\hline $\begin{array}{l}\text { Slit lamp } \\
\text { examination }\end{array}$ & $\mathrm{X}$ & $\mathrm{X}$ & $\mathrm{X}$ & $\mathrm{X}$ \\
\hline Schirmer test ${ }^{\star \star}$ & $X$ & & & \\
\hline
\end{tabular}

OSDI: Ocular Surface Disease Index; T-BUT: Fluorescein tear film break-up time.

* Performed only if OSDI $>13 ; * *$ Performed at least 15 minutes after the end of the previous procedure 
Table 2. Preliminary Ocular Surface Frailty Index composition

\begin{tabular}{|c|c|c|}
\hline 1. Connective tissue diseases & $\begin{array}{l}\text { No } \\
\text { Yes }\end{array}$ & $\begin{array}{l}0 \text { points } \\
1 \text { point }\end{array}$ \\
\hline 2. Diabetes & $\begin{array}{l}\text { No } \\
\text { Yes }\end{array}$ & $\begin{array}{l}0 \text { points } \\
1 \text { point }\end{array}$ \\
\hline 3. Rosacea & $\begin{array}{l}\text { No } \\
\text { Yes }\end{array}$ & $\begin{array}{l}0 \text { points } \\
1 \text { point }\end{array}$ \\
\hline 4. Thyroid malfunction & $\begin{array}{l}\text { No } \\
\text { Yes }\end{array}$ & $\begin{array}{l}0 \text { points } \\
1 \text { point }\end{array}$ \\
\hline 5. Psychiatric conditions* & $\begin{array}{l}\text { No } \\
\text { Yes }\end{array}$ & $\begin{array}{l}0 \text { points } \\
1 \text { point }\end{array}$ \\
\hline 6. Systemic medications ${ }^{* *}$ & $\begin{array}{l}\text { No } \\
\text { Yes }\end{array}$ & $\begin{array}{l}0 \text { points } \\
1 \text { point }\end{array}$ \\
\hline 7. Hormone replacement therapy & $\begin{array}{l}\text { No } \\
\text { Yes }\end{array}$ & $\begin{array}{l}0 \text { points } \\
1 \text { point }\end{array}$ \\
\hline 8. Computer use C $^{* * *}$ & $\begin{array}{l}\text { No } \\
\text { Yes }\end{array}$ & $\begin{array}{l}0 \text { points } \\
1 \text { point }\end{array}$ \\
\hline 9. Ocular allergy & $\begin{array}{l}\text { No } \\
\text { Yes }\end{array}$ & $\begin{array}{l}0 \text { points } \\
1 \text { point }\end{array}$ \\
\hline 10. History of refractive surgery & $\begin{array}{l}\text { No } \\
\text { Yes }\end{array}$ & $\begin{array}{l}0 \text { points } \\
1 \text { point }\end{array}$ \\
\hline 11. Contact lenses wear & $\begin{array}{l}\text { No } \\
\text { Yes }\end{array}$ & $\begin{array}{l}0 \text { points } \\
1 \text { point }\end{array}$ \\
\hline 12. Topical drugs ${ }^{\star \star * *}$ & $\begin{array}{l}\text { No } \\
\text { Yes }\end{array}$ & $\begin{array}{l}0 \text { points } \\
1 \text { point }\end{array}$ \\
\hline 13. Presence of conjunctivochalasis & $\begin{array}{l}\text { No } \\
\text { Yes }\end{array}$ & $\begin{array}{l}0 \text { points } \\
1 \text { point }\end{array}$ \\
\hline 14. Pterygium & $\begin{array}{l}\text { No } \\
\text { Yes }\end{array}$ & $\begin{array}{l}0 \text { points } \\
1 \text { point }\end{array}$ \\
\hline $\begin{array}{l}\text { 15. TBUT } \\
\text { with fluorescein }\end{array}$ & $\begin{array}{l}\geq 10 s \\
8-9 s \\
6-7 s \\
4-5 s \\
2-3 s \\
0-1 s\end{array}$ & $\begin{array}{l}0 \text { points } \\
0,20 \text { points } \\
0,40 \text { points } \\
0,60 \text { points } \\
0,80 \text { points } \\
1 \text { point }\end{array}$ \\
\hline $\begin{array}{l}\text { 16. Fluorescein staining } \\
\text { (Oxford scale) }\end{array}$ & $\begin{array}{l}\text { Grade } 0 \\
\text { Grade } 1 \\
\text { Grade } 2 \\
\text { Grade } 3 \\
\text { Grade } 4 \\
\text { Grade } 5\end{array}$ & $\begin{array}{l}0 \text { points } \\
0,20 \text { points } \\
0,40 \text { points } \\
0,60 \text { points } \\
0,80 \text { points } \\
1 \text { point }\end{array}$ \\
\hline $\begin{array}{l}\text { 17. Meibomian glands expressibility } \\
\text { (digital expression) }\end{array}$ & $\begin{array}{l}\text { Grade 0: clear meibum easily expressed } \\
\text { Grade 1: cloudy meibum expressed with } \\
\text { mild pressure } \\
\text { Grade 2: cloudy meibum expressed with } \\
\text { moderate pressure } \\
\text { Grade } 3: \text { meibum not expressed with } \\
\text { more than moderate pressure }\end{array}$ & $\begin{array}{l}0 \text { points } \\
0,33 \text { points } \\
0,66 \text { points } \\
1 \text { point }\end{array}$ \\
\hline
\end{tabular}




\begin{tabular}{|l|l|l|}
\hline 18. LIPCOF & Grade 0 & 0 points \\
& Grade 1 & 0,33 points \\
& Grade 2 & 0,66 points \\
& Grade 3 & 1 point \\
\hline 19. Schirmer test & $\geq 10 \mathrm{~mm}$ & 0 points \\
without anesthesia & $8-9 \mathrm{~mm}$ & 0,20 points \\
& $6-7 \mathrm{~mm}$ & 0,40 points \\
& $4-5 \mathrm{~mm}$ & 0,60 points \\
& $2-3 \mathrm{~mm}$ & 0,80 points \\
& $0-1 \mathrm{~mm}$ & 1 point \\
\hline
\end{tabular}

*: Including affective, somatoform disorders, anxiety and depression

**: Current use of at least one of the following drugs: anticholinergic, antihistamines, antidepressants, anxiolytics, betablockers, diuretics OR concomitant use of at least 5 systemic drugs $* * *$ : Exposure $>4$ hours/day

****: Current use of at least one of the following topical drugs: antiglaucomatous, antiallergic, antiviral, decongestants, miotics, mydriatics, non-steroidal anti-inflammatory OR at least 3 drops/day BAK preserved 
Table 6. Matrix presentation of Ocular Surface Frailty Index Content Validity

\begin{tabular}{|c|c|c|c|c|}
\hline $\begin{array}{l}\text { DOMAINS } \\
\text { ITEMS }\end{array}$ & $\begin{array}{l}\text { Tear film } \\
\text { instability }\end{array}$ & $\begin{array}{c}\text { Ocular surface } \\
\text { inflammation }\end{array}$ & $\begin{array}{l}\text { Neuro-sensory } \\
\text { abnormalities }\end{array}$ & $\begin{array}{c}\text { Ocular surface } \\
\text { damage }\end{array}$ \\
\hline $\begin{array}{l}\text { Connective tissue } \\
\text { diseases }\end{array}$ & & $\mathbf{x}$ & & $\mathbf{x}$ \\
\hline Thyroid malfunction & & $\mathbf{x}$ & & \\
\hline $\begin{array}{l}\text { Psychiatric } \\
\text { conditions }\end{array}$ & & & $\mathbf{x}$ & \\
\hline Computer use & $\mathbf{x}$ & & & \\
\hline Ocular allergy & $\mathbf{x}$ & $\mathbf{x}$ & & $\mathbf{x}$ \\
\hline $\begin{array}{l}\text { History of refractive } \\
\text { surgery }\end{array}$ & & & $\mathbf{x}$ & $\mathbf{x}$ \\
\hline Topical drugs & & $\mathbf{x}$ & $x$ & $\mathbf{x}$ \\
\hline TBUT & $\mathbf{x}$ & & & \\
\hline $\begin{array}{l}\text { Meibomian glands } \\
\text { expressibility }\end{array}$ & $\mathbf{x}$ & & & $\mathbf{x}$ \\
\hline LIPCOF & $\mathbf{x}$ & & & \\
\hline Diabetes & & & $\mathbf{X}$ & \\
\hline Rosacea & $\mathbf{x}$ & $\mathbf{x}$ & & $\mathbf{x}$ \\
\hline Systemic medications & & $\mathbf{x}$ & $\mathbf{x}$ & \\
\hline $\begin{array}{l}\text { Hormone replacement } \\
\text { therapy }\end{array}$ & & $\mathbf{x}$ & & \\
\hline Contact lens wear & $\mathbf{x}$ & & $\mathbf{X}$ & $\mathbf{X}$ \\
\hline Conjunctivochalasis & $\mathbf{X}$ & & & \\
\hline Pterygium & $\mathbf{X}$ & $\mathbf{X}$ & & \\
\hline Fluorescein staining & & & & $\mathbf{X}$ \\
\hline Schirmer test & $\mathbf{X}$ & & & $\mathbf{X}$ \\
\hline
\end{tabular}

Bold: items included in the final OSFI;

Italics: items included in the preliminary OSFI but excluded from the final OSFI. 
Click here to access/download

\section{ICMJE COI Form \\ OPHTHA_COI Villani.pdf}




\section{Click here to access/download ICMJE COI Form \\ OPHTHA_COI Marelli.pdf}




\section{Click here to access/download \\ ICMJE COI Form
OPHTHA_COI Lucentini.pdf \\ ICMJE COI Form
OPHTHA_COI Lucentini.pdf}




\section{Click here to access/download ICMJE COI Form \\ OPHTHA_COI Luccarelli.pdf}


Click here to access/download

\section{ICMJE COI Form OPHTHA_COI Serafino.pdf}


Click here to access/download
ICMJE COI Form
OPHTHA_COI Nucci.pdf

Click here to access/download
ICMJE COI Form
OPHTHA_COI Nucci.pdf Click here to access/download
ICMJE COI Form
OPHTHA_COI Nucci.pdf

Click here to access/download
ICMJE COI Form
OPHTHA_COI Nucci.pdf

(n)

Click here to access/download
ICMJE COI Form
OPHTHA_COI Nucci.pdf

ICMJE COI Form
ICMead
PHTHA_COI Nucci.pdf ck here to access/download
ICMJE COI Form
HTHA_COI Nucci.pdf ICMJE COI Form
PHTHA_COI Nucci.pdf 更 (n) 


\section{Click here to access/download \\ ICMJE COI Form OPHTHA_COI Bonsignore.pdf}




\section{Click here to access/download ICMJE COI Form OPHTHA_COI Sacchi.pdf}




\section{Ophthalmology ${ }^{\circledR}$, Ophthalmology ${ }^{\circledR}$ Retina, and Ophthalmology ${ }^{\circledR}$ Glaucoma Author Contributorship Statement}

The journal adheres to the Uniform Requirements set by the International Committee of Medical Journal Editors (http://www.icmje.org/) for authorship. To qualify for authorship, authors must make substantial contributions to the intellectual content of the paper in each of the four following categories:

1. Substantial contributions to conception and design of the work; or the acquisition, analysis, or interpretation of data for the work; AND

2. Drafting the work or revising it critically for important intellectual content; AND

3. Final approval of the version to be published; AND

4. Agreement to be accountable for all aspects of the work in ensuring that questions related to the accuracy or integrity of any part of the work are appropriately investigated and resolved.

It is the responsibility of the corresponding author, prior to submitting the manuscript, to confirm that each coauthor meets the requirements for authorship. Please list all authors of the manuscript on the Contributorship Statement form below. The form need not be uploaded at the time of original manuscript submission but rather if/when the Editorial Board invites revision.

By submitting this form, the corresponding author acknowledges that each author has read the statement on authorship responsibility and contribution to authorship. In the table below, please designate the contributions of each author. Any relevant contribution not described in the four columns can be added under "Other contributions." Please note that the list of contributions will publish with the manuscript should it be accepted. Thank you.

TITLE OF ARTICLE: The Ocular Surface Frailty Index as a predictor of ocular surface sympton AUthors: Edoardo Villani, Francesco Bonsignore, Luca Marelli, Stefano Lucentini, Save

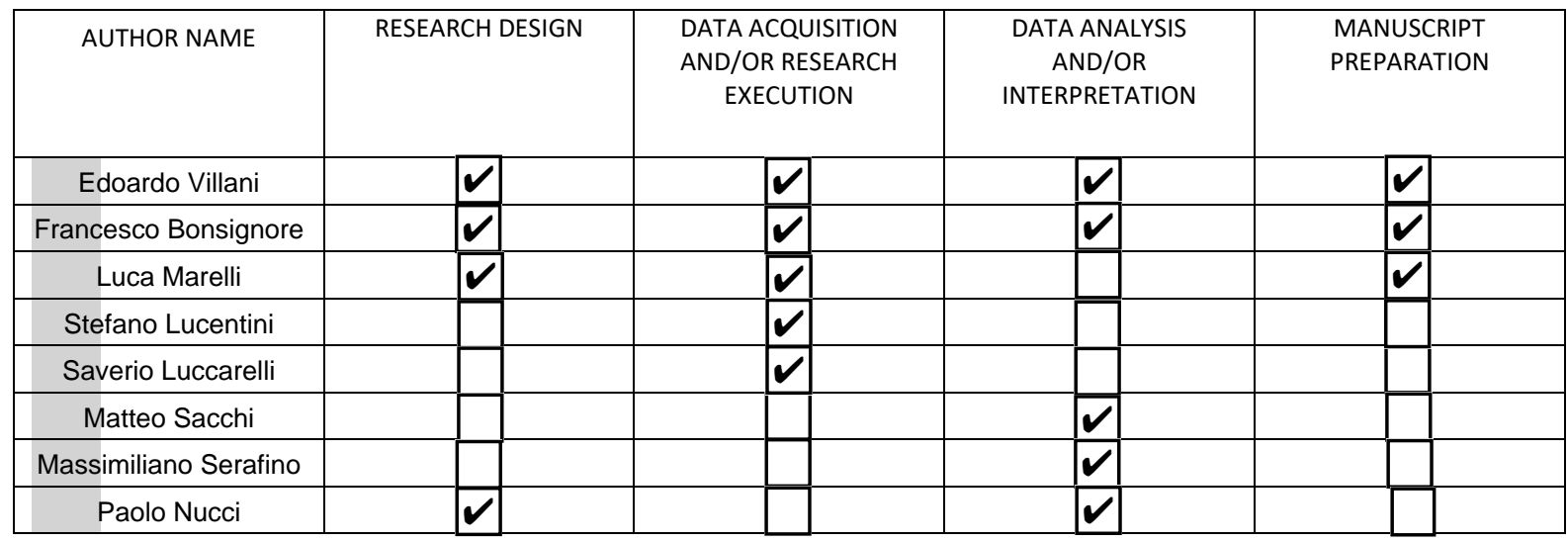

OTHER CONTRIBUTIONS: 